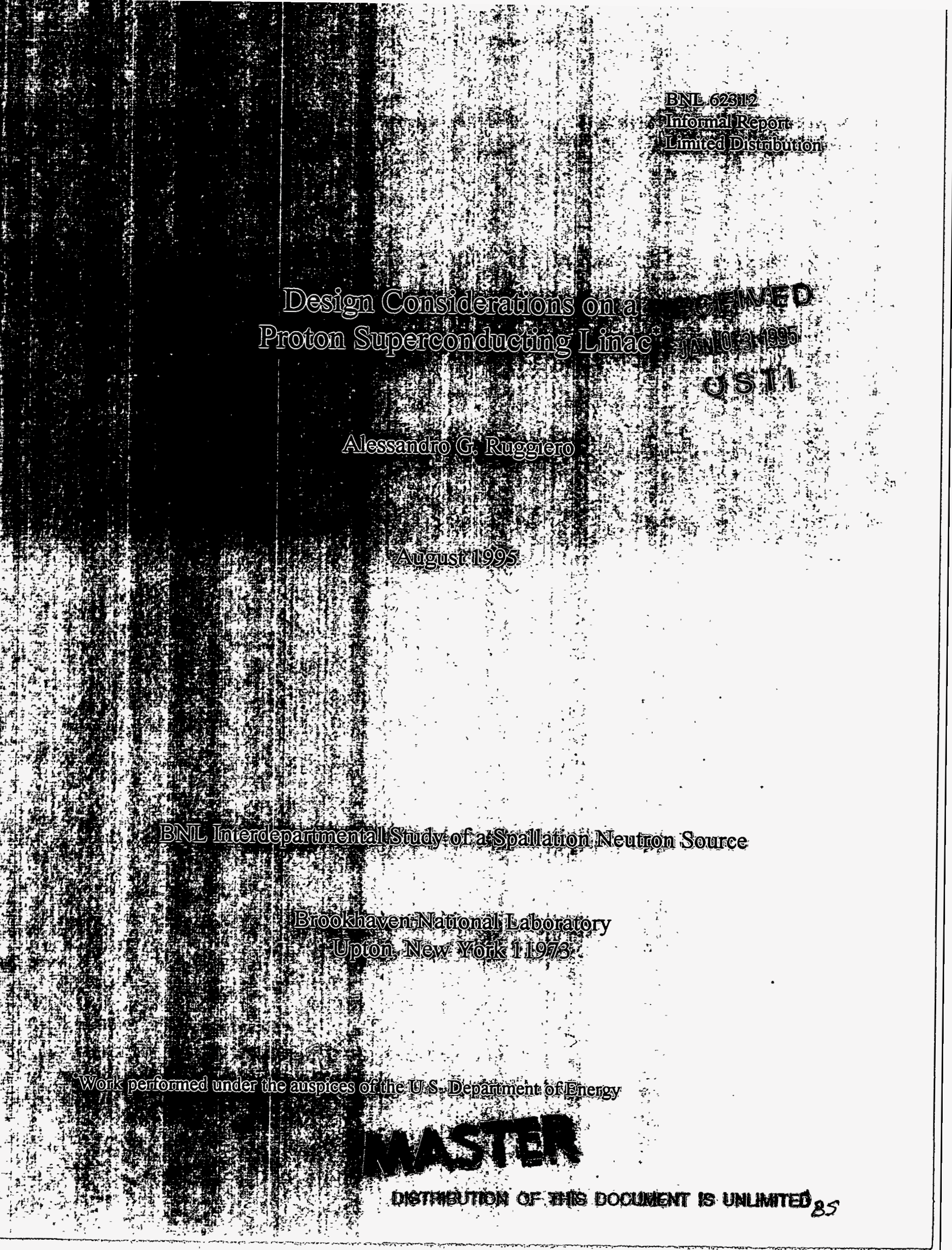




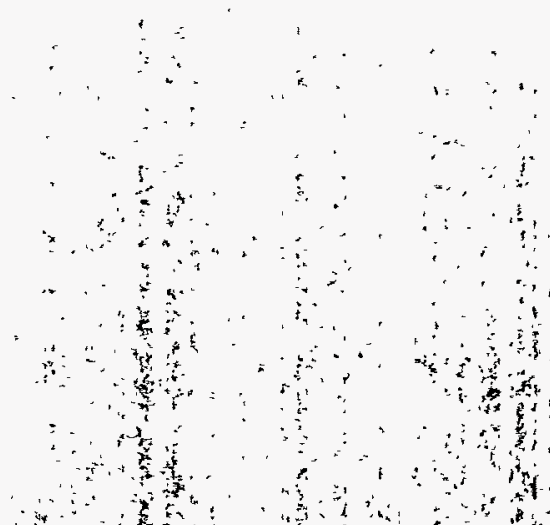

This report was prepared as an account of work sponsore Neither the United States nor the:United States Department of nor any of their contractors subeontractors, or their enploy

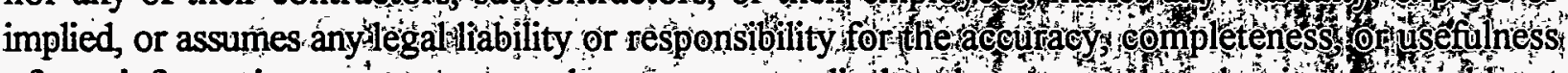

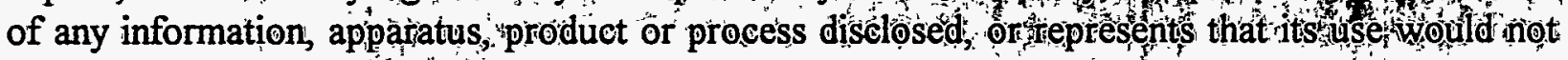
infringe privately owned rights. 
BNL 62312

Informal Report

Limited Distribution

\title{
Design Considerations on a Proton Superconducting Linac*
}

\author{
Alessandro G. Ruggiero
}

August 1995

DISCLAIMER

This report was prepared as an account of work sponsored by an agency of the United States Government. Neither the United States Government nor any agency thereof, nor any of their employees, makes any warranty, express or implied, or assumes any legal liability or responsibility for the accuracy, completeness, or usefulness of any information, apparatus, product, or process disclosed, or represents that its use would not infringe privately owned rights. Reference herein to any specific commercial product, process, or service by trade name, trademark, manufacturer, or otherwise does not necessarily constitute or imply its endorsement, recommendation, or favoring by the United States Government or any agency thereof. The views and opinions of authors expressed herein do not necessarily state or reflect those of the United States Government or any agency thereof.

\section{BNL Interdepartmental Study of a Spallation Neutron Source}

\author{
Brookhaven National Laboratory \\ Upton, New York 11973
}

Work performed under the auspices of the U.S. Department of Energy 


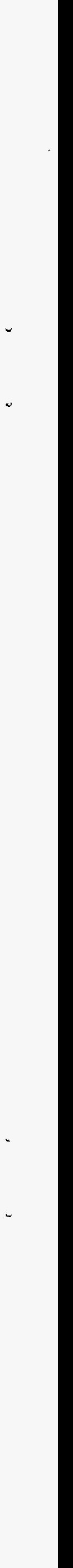




\title{
Design Considerations on a Proton Superconducting Linac
}

\author{
Alessandro G. Ruggiero \\ Brookhaven National Laboratory \\ August 1995
}

\begin{abstract}
We analyze the longitudinal motion of a single proton in a superconducting linear accelerator. We derive the linearized equations of motion, and develop a matrix formalism to represent the progress of motion. The goal is to provide a tool which can be easily included in a computer code for the design of superconducting proton linacs. In particular we determine the stability conditions, and the amount of motion mismatch resulting from the presence of drift insertions, and from the rate of acceleration. Space-charge effects have not been included in the analysis. We complement the analysis with considerations of the rf and cryogenic power requirements, of the pulsed mode of operation, and of the beam transverse confinement. We conclude with an example of a Spallation Neutron Source.
\end{abstract}

\section{Introduction}

We consider a section of a superconducting linear accelerator for the acceleration of protons between the initial energy $E_{1}$ and the final energy $E_{2}$ which correspond to a velocity range, expressed in terms of the relativistic velocity factor, between $\beta_{1}$ and $\beta_{2}$.

We assume that the accelerator is a sequence of a number of identical periods, as shown in Figure 1 . Each period is made of a cryo-module of length $l_{\text {cryo }}$ and of an insertion of length $l_{\text {ins. }}$. The insertion is needed for the placement of focussing quadrupoles, vacuum pumps, steering magnets, beam diagnostic devices, bellows and flanges. It can be either at room temperature or in a cryostat as well. The cryo-module includes $M$ identical cavities each of $N$ identical cells, and each having a length $L=N l_{c}$, where $l_{c}$ is the length of a cell. Cavities are separated from each other by a drift space $d$. An extra drift of length $l_{w}$ may be added internally, on both sides of the cryo-module, to provide the transition between cold and warm regions. Thus,

$l_{\text {cryo }}=M N l_{\mathrm{c}}+(M-1) d+2 l_{\mathrm{w}}$

There are two symmetric intervals: a minor one, between the two middle-points $A$ and $B$, as shown in Figure 1, which defines the interval of a cavity of length $L+d$; and a major one, between the two middle-points $C$ and D, also shown in Figure 1, which defines the range of a period of total length $l_{\text {cryo }}+l_{\text {ing }}$. Thus the topology of a period can be represented as a drilt of length $g$, followed by $M$ cavity intervals, and a final drift of length $g$, where

$g=l_{\mathrm{w}}+\left(l_{\mathrm{ins}}-d\right) / 2$

Our goal is to determine the motion of a test particle in the longitudinal direction. After having 
derived the equations of motion in the linear approximation, we shall develop a matrix method to describe the motion. For this purpose, we assume that all periods are identical, and that there is no energy change of the reference particle across a cryo-module. Acceleration is provided from one period to the next. The transfer-matrix method is very suitable for inclusion in a tracking or design computer code. Also, it allows estimation of the stability of the motion which may be disrupted by the insertion of drifts. Moreover, it is convenient for the estimation of motion mismatch in case the acceleration occurs at too large a rate.

At the end, we develop an operation model based on the assumption of constant energy gain per period. The choice of cryo-modules having all identical geometry and cavity/cell configuration is dictated by cost and construction handling. But there is, nevertheless, a penalty, in most cases of minor magnitude, due to the reduced transit-time-factors when crossing cavity cells, all with length adjusted to a common $\beta$ value, which does not correspond to the particle's instantaneous velocity.

Longitudinal space-charge forces have not been included in the present analysis.
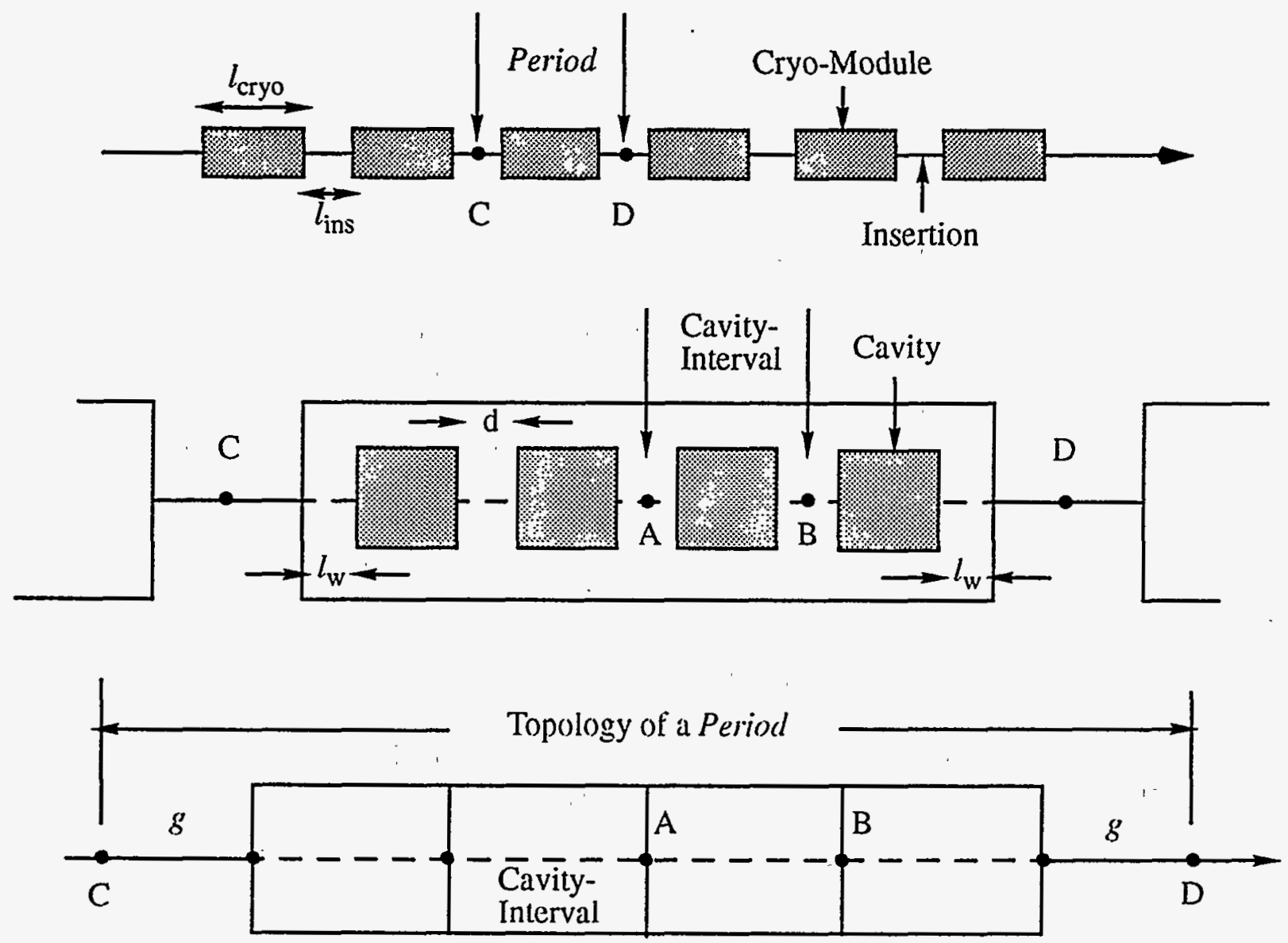

Figure 1. Configuration of a Proton Superconducting Linear Accelerator 


\section{The Linearized Equations of Motion}

To describe the longitudinal motion of a single proton, let us take the canonically conjugated variables: the time delay $\tau$ and the energy difference $\varepsilon$ with respect to the reference particle. We take also the longitudinal path length $s$ as the independent variable. In the following a prime (') will denote derivative with respect to $s$.

We have

$$
\tau^{\prime}=1 / \mathrm{v}-1 / \mathrm{v}_{\mathrm{s}},
$$

where $v$ is the velocity of the test particle, $v_{s}$ that of the reference particle. After linearization,

$$
\tau^{\prime}=-\varepsilon / c \beta_{s}^{3} \gamma_{s}^{3} E_{0},
$$

where $c$ is the light velocity, $E_{0}$ is the proton energy at rest, and $\beta_{s}, \gamma_{s}$, respectively, the velocity and the energy relativistic factors of the reference particle.

If $E$ is the total energy of the test particle, and $E_{s}$ that of the reference particle,

$$
\varepsilon=E-E_{s} \text {. }
$$

The energy equations are

$$
\begin{aligned}
& \mathrm{E}^{\prime}=e \mathrm{E}_{\mathrm{acc}} \cos (\omega t), \\
& \mathrm{E}_{\mathrm{s}}^{\prime}=e \mathrm{E}_{\mathrm{acc}} \cos \left(\omega t_{\mathrm{s}}\right),
\end{aligned}
$$

where $e$ is the proton electric charge, $E_{\text {acc }}$ the accelerating peak field, $\omega$ the angular frequency of the accelerating field, and $t, t_{\mathrm{s}}$ the traversal time-instants through the rf cavities, respectively, of the test and the reference particle, and

$\tau=t-t_{\mathrm{s}}$.

Then

$\varepsilon^{\prime}=e \mathrm{E}_{\mathrm{acc}}\left[\cos (\omega t)-\cos \left(\omega t_{\mathrm{s}}\right)\right]$.

After linearization

$$
\varepsilon^{\prime} \doteq-e \mathrm{E}_{\mathrm{acc}}\left(\sin \phi_{\mathrm{s}}\right) \omega \tau,
$$

where $\phi_{\mathrm{s}}=\omega t_{\mathrm{S}}$ is the synchronous rf phase angle.

Eq.s (4 and 10) are the linear equations of motion of the test particle. For a segment of the accelerating structure, short enough to neglect the variation of $\beta_{s}{ }^{3} \gamma_{s}^{3}$, by combining the two equations, 
we derive

$\tau^{\prime \prime}+K^{2} \tau=0$

with the restoring parameter

$K=\left[e \mathrm{E}_{\mathrm{acc}}\left(-\sin \phi_{\mathrm{s}}\right) \omega / \mathrm{c} \beta_{\mathrm{s}}^{3} \gamma_{\mathrm{s}}^{3} \mathrm{E}_{0}\right]^{1 / 2}=\Omega_{\mathrm{s}} / \mathrm{c} \beta_{\mathrm{s}}$,

and $\Omega_{s}$ is the longitudinal oscillation angular frequency.

\section{Development of the Matrix Method}

Let us now take $\tau$ and $\tau^{\prime}$ as the variables that describe the motion of the test particle. $\tau^{\prime}$ is related to the energy difference $\varepsilon$ through Eq. (4). The status of motion can be represented by a columnvector of the two components $\tau$ and $\tau^{\prime}$ to which we can apply a properly defined $2 \times 2$ transfer matrices. In a drift of length $l$, the transfer matrix is simply

$\mathrm{M}_{\text {drift }}=\left(\begin{array}{ll}1 & l \\ 0 & 1\end{array}\right)$

whereas in a rf cavity of length $L$

$\mathrm{M}_{\text {cavity }}=\left(\begin{array}{cc}\cos \theta & (\sin \theta) / K \\ -K \sin \theta & \cos \theta\end{array}\right)$,

where the rotation angle $\theta=K L$.

Define the transfer matrix $M_{c}$ between the two symmetry points $A$ and $B$ of a cavity-interval, as shown in Figure 1,

$M_{c}=\left(\begin{array}{cc}1 & d / 2 \\ 0 & 1\end{array}\right)\left(M_{\text {cavity }}\right)\left(\begin{array}{ll}1 & d / 2 \\ 0 & 1\end{array}\right)$.

Because of symmetry, this matrix can be written as follows

$M_{c}=\left(\begin{array}{cc}\cos \mu_{c} & \beta_{c} \sin \mu_{c} \\ -\left(\sin \mu_{c}\right) / \beta_{c} & \cos \mu_{c}\end{array}\right)$,

where, denoting with $\eta$ the ratio $d / L$,

$K \beta_{\mathrm{c}}=\left(1-\theta^{2} \eta^{2} / 4+\theta \eta \cot \theta\right)^{1 / 2}$, 
$L \operatorname{tg} \mu_{\mathrm{c}}=\beta_{\mathrm{c}} \theta /(\cot \theta-\theta \eta / 2)$.

It is easy to derive the transfer matrix corresponding to the sequence of $M$ identical cavity intervals. It is given by

$\mathrm{M}_{\mathrm{c}}{ }^{M}=\left(\begin{array}{cc}\cos \left(M \mu_{\mathrm{c}}\right) & \beta_{\mathrm{c}} \sin \left(M \mu_{\mathrm{c}}\right) \\ -\left[\sin \left(M \mu_{\mathrm{c}}\right)\right] / \beta_{\mathrm{c}} & \cos \left(M \mu_{\mathrm{c}}\right)\end{array}\right)$.

We can also derive the total transfer matrix per period taken between middle-points $C$ and $D$ as shown in Figure 1.

$\mathrm{M}_{\mathrm{c}}=\left(\begin{array}{ll}1 & g \\ 0 & 1\end{array}\right)\left(\mathrm{M}_{\mathrm{c}}{ }^{M}\right)\left(\begin{array}{ll}1 & g \\ 0 & 1\end{array}\right)$,

where $g$ is given by Eq. (2). Because of symmetry, the transfer matrix per period has a form similar to Eq. (16), namely

$\mathrm{M}_{\mathrm{p}}=\left(\begin{array}{cc}\cos \mu_{\mathrm{p}} & \beta_{\mathrm{p}} \sin \mu_{\mathrm{p}} \\ -\left(\sin \mu_{\mathrm{p}}\right) / \beta_{\mathrm{p}} & \cos \mu_{\mathrm{p}}\end{array}\right)=\left(\begin{array}{cc}\mathrm{m}_{11} & \mathrm{~m}_{12} \\ \mathrm{~m}_{21} & \mathrm{~m}_{22}\end{array}\right)$,

where

$\beta_{\mathrm{p}}=\left\{\beta_{\mathrm{c}}^{2}-g^{2}+2 g \beta_{\mathrm{c}} \cot \left(M \mu_{\mathrm{c}}\right)\right\}^{1 / 2}$,

$\operatorname{tg} \mu_{\mathrm{p}}=\beta_{\mathrm{p}} /\left[\beta_{\mathrm{c}} \cot \left(M \mu_{\mathrm{c}}\right)-g\right]$.

\section{Beam Bunch Dimensions}

The phase advance of the Iongitudinal oscillations is given by $\mu_{\mathrm{c}}$ and $\mu_{\mathrm{p}}$, respectively, per cavity interval and per period. The amplitude function, which describes the beam bunch extension, has values $\beta_{c}$ and $\beta_{p}$, respectively, between cavity intervals (middle-points $A$ and $B$ of Figure 1 ) and between periods (middle-points $C$ and $D$ of Figure 1 ).

Let $\Delta \tau$ be half of the bunch length in time units, and $\Delta \varepsilon$ be half of the energy spread. In those middle points with symmetry, the bunch ellipse in the phase plane $(\tau, \varepsilon)$ is upright; consequently the bunch area

$S=\pi \Delta \tau \Delta \varepsilon$

If the bunch area $S$ is known, one can then estimate the bunch length from

$\Delta \tau=\left(S \beta_{c, p} / \pi c \beta_{s}^{3} \gamma_{s}^{3} E_{0}\right)^{1 / 2}$ 
Once the bunch length $\Delta \tau$ and area $S$ are know, one derives the energy spread $\Delta \varepsilon$ from Eq. (24).

\section{Stability of Motion}

For the motion to be stable across a cavity interval or across a period, the values of the amplitude function given by Eq.s (17 and 22) must satisfy the relation

$\beta_{c, p}>0$

The value $\beta_{c}$ is plotted in Figure 2 versus the rotation angle $\theta$ for several values of the ratio $\eta$. In the limit $d=0, \beta_{\mathrm{c}}=1 / K$, and the motion is always stable. As the length of the insertion increases, with respect to the cavity length $L$, the permissible range of values of the rotation angle, that is of the accelerating gradient, reduces. The limit of stability, which is the maximum permissible value of $\theta$, is given in Figure 3 where it is plotted versus the ratio $\eta$.

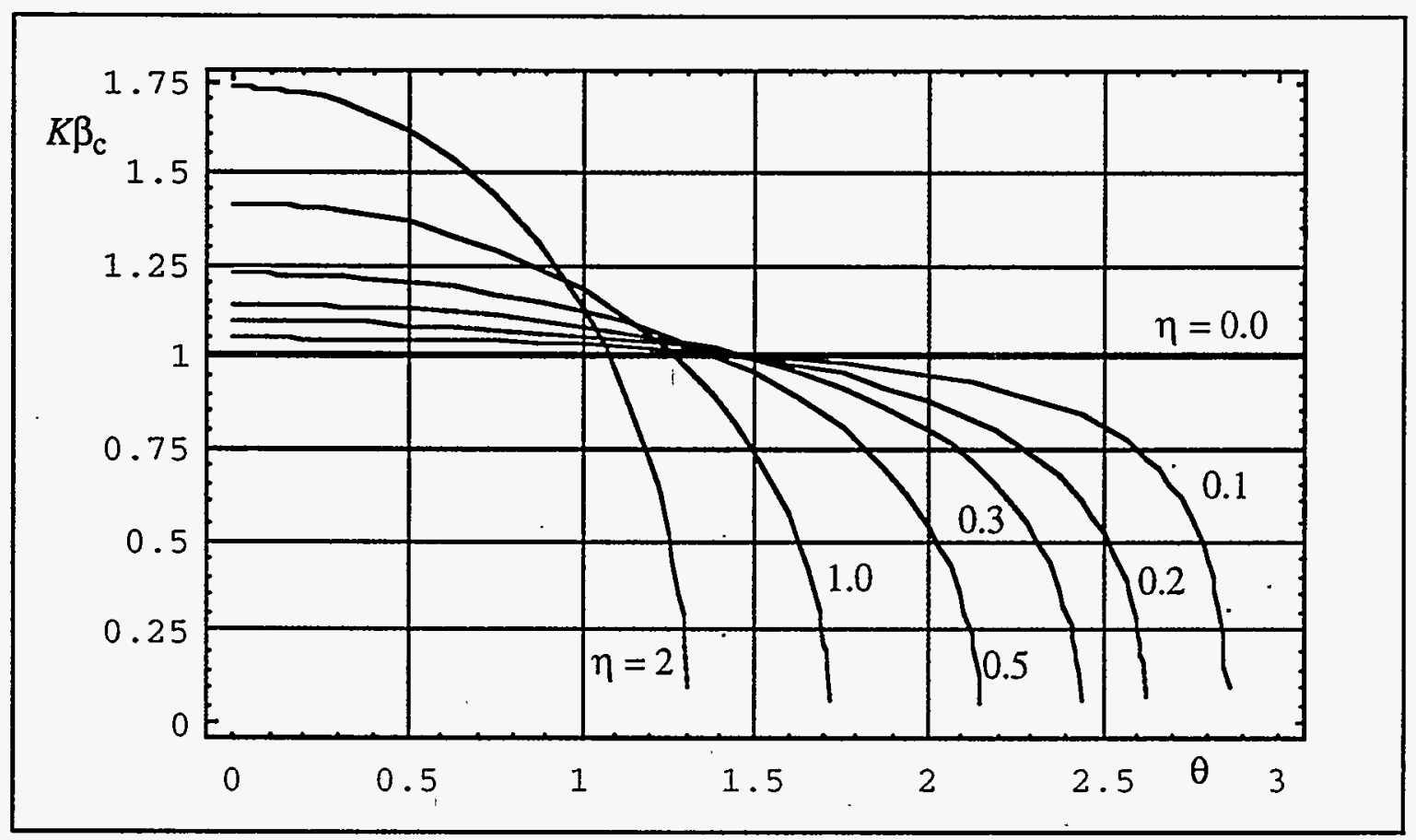

Figure 2. Plot of $K \beta_{\mathrm{c}}$ versus the rotation angle $\theta$, for several values of the ratio $\eta=d / L$.

Similarly, the amplitude value $\beta_{\mathrm{p}}$ is plotted in Figure 4 versus the phase advance $M \mu_{\mathrm{c}}$ corresponding to $M$ cavities, for several values of the ratio $g / \beta_{\mathrm{c}}$. It is seen that in the limit $g=0, \beta_{\mathrm{p}}=\beta_{\mathrm{c}}$, and the motion is everywhere stable. 


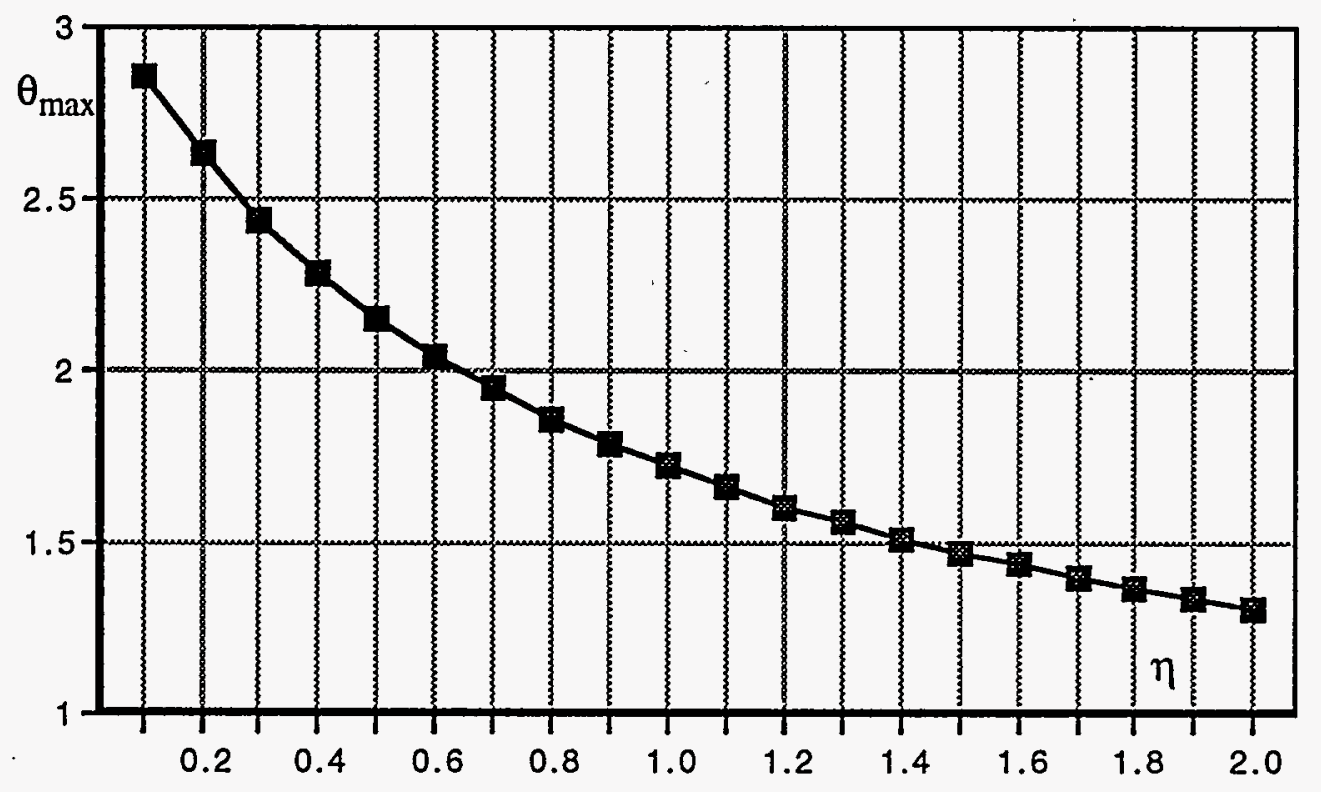

Figure 3. Plot of the rotation angle $\theta$ at the limit of stability versus the ratio $\eta=d / L$.

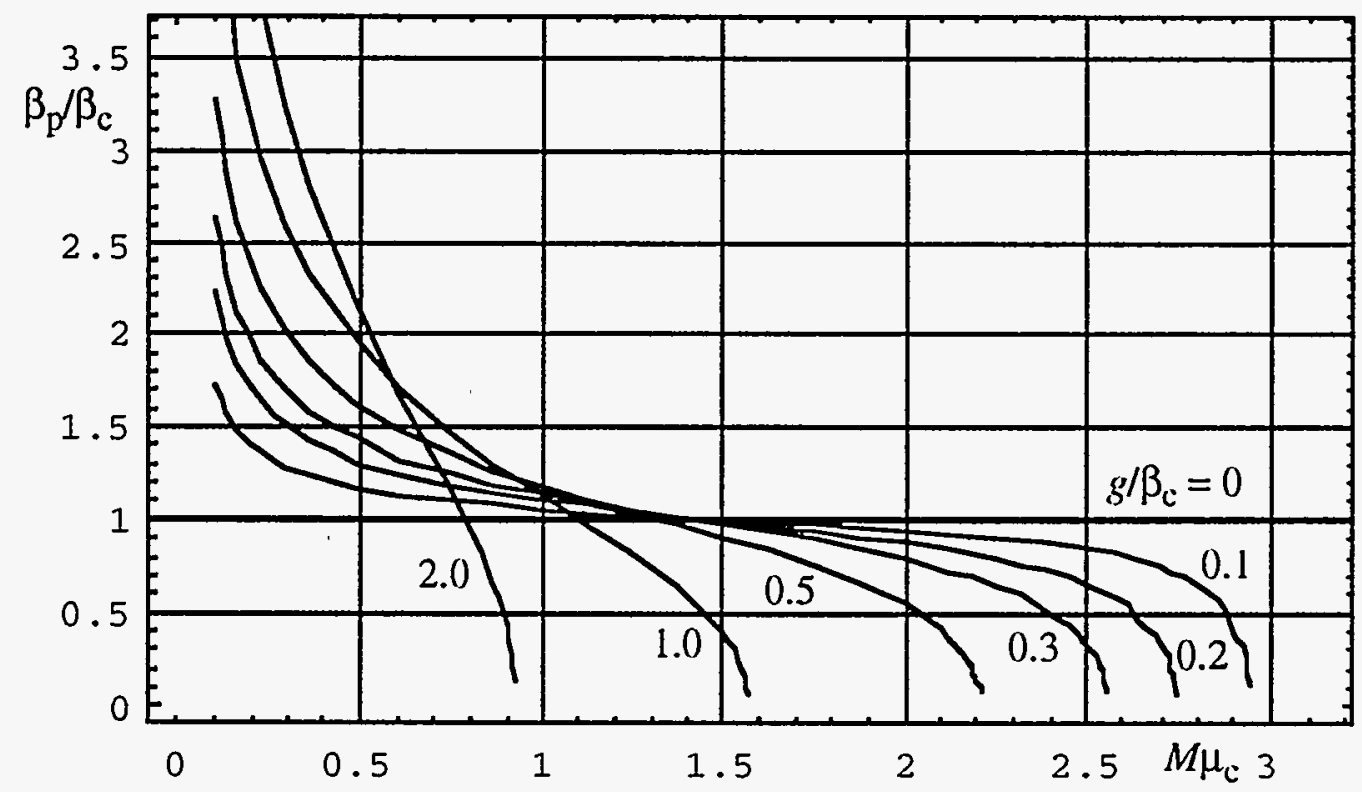

Figure 4. Plot of the ratio $\beta_{p} / \beta_{c}$ versus $M \mu_{c}$, for several values of the ratio $g / \beta_{c}$. 


\section{Mismatch of Motion}

We have assumed that the restoring parameter $K$ does not change across the length of a period. This assumption is justified when indeed the acceleration rate is not too high, and the energy change of the reference particle is small compared to the total kinetic energy.

Complete matching of the motion as it progresses down the length of the linear accelerator is achieved by requiring that the amplitude value $\beta_{\mathrm{p}}$ remains constant from a period to another. From Eq. (22) we infer that this requires that in turn also $\beta_{c}$ and the phase advance $\mu_{c}$ per cavityinterval remain also unchanged. That is, from Eq.s (17 and 18), that the rotation angle $\theta$, and thus the restoring parameter $K$ are also constant. For a constant accelerating frequency $\omega$, and constant If phase angle $\phi_{\mathrm{s}}$, we derive the following condition for complete matching

$\mathrm{E}_{\mathrm{acc}} / \beta_{\mathrm{s}}^{3} \gamma_{\mathrm{s}}^{3}=$ constant

which assigns how the accelerating field $E_{\text {acc }}$ has to vary with the beam energy.

This condition is usually difficult to meet in practice. Thus a different, simpler mode of operation is proposed which assumes a constant energy gain per period, that is per cryo-module. Since all the cryo-modules are identical, with the same geometry, number of cavities and cells per cavity, this mode of operation leads to the same energy gain also per cavity and per cell everywhere. If we denote with $U$ the energy gain per cell, the energy gain per cavity is $M U$ and that per period is $M N U$. From Eq. (7)

$U=\quad \mathrm{e} l_{\mathrm{c}} \mathrm{E}_{\mathrm{acc}} \cos \phi_{\mathrm{s}}$.

The constant energy-gain mode of operation yields to a constant accelerating field $\mathrm{E}_{\text {acc }}$, so that the value of the restoring parameter $K$ will vary and decrease with the beam energy. This will cause a continuous mismatch of the particle motion, that is a beam bunch dilution of an amount which depends on the acceleration rate, and on the length of the drift insertions. In analogy to the conventional approach used to describe the transverse motion, a beam bunch can be made to correspond to an ellipse in the phase space $\left(\tau, \tau^{\prime}\right)$. Between periods, the ellipse is described by the local amplitude function $\beta_{\mathrm{p}}$ and the inclination function $\alpha_{\mathrm{p}}$. To estimate the amount of mismatch as the motion progress, we assume that the dimensions of the beam bunch are exactly matched at the entrance of the linac section, where $\alpha_{\mathrm{p}}=0$ and $\beta_{\mathrm{p}}$ is given by Eq.(22). It is well known then how to estimate the bunch ellipse rotation, dilation or contraction from one period to the next. This will yield an amplitude functions which in general will be different from $\beta_{p}$, and an inclination function with values oscillating around zero. The propagation of the ellipse orientation and elongation/dilation across one period. (from midpoint " 1 " to midpoint " 2 ") is given by

$$
\left(\begin{array}{l}
\beta_{p} \\
\alpha_{p} \\
\gamma_{p}
\end{array}\right)_{2}=\left(\begin{array}{ccc}
m_{11}^{2} & -2 m_{11} m_{12} & m_{12}^{2} \\
-m_{21} m_{11} & 1+2 m_{12} m_{21} & -m_{12} m_{22} \\
m_{21}^{2} & -2 m_{22} m_{21} & m_{22}
\end{array}\right)\left(\begin{array}{l}
\beta_{p} \\
\alpha_{p} \\
\gamma_{p}
\end{array}\right)_{1}
$$

where $\beta_{p} \gamma_{p}=1+\alpha_{p}^{2}$, and the elements $m_{i j}$ are given in Eq. (21). 


\section{RF Power Considerations}

The total rf power required to operate one cryo-module is the sum of three contributions:

$\mathrm{P}_{\mathrm{rf}}=\mathrm{P}_{\mathrm{b}}+\mathrm{P}_{\mathrm{w}}+\mathrm{P}_{\mathrm{HOM}}$

where the beam power, denoting with $I_{\mathrm{b}}$ the beam current,

$\mathrm{P}_{\mathrm{b}}=\quad M N U I_{\mathrm{b}} / e$.

$P_{w}$ is the wall-dissipated power, and $P_{H O M}$ the power dissipated to the cavity high-order resonating modes. In a superconducting linac for protons, one expects $P_{w}+P_{H O M} \ll P_{b}$, so that the if power requirement is dominated by the beam power. Denoting with $\mathrm{P}_{\text {coup }}$ the if power in each of the rf couplers driving the cavity system, and by $n_{\text {coup }}$ the number of couplers per cryo-module

$\mathrm{P}_{\text {coup }} \sim \mathrm{P}_{\mathrm{b}} / \mathrm{n}_{\text {coup }}$.

This amount is constant and the same from one period to the next.

The energy gain per cell $U$ is given by Eq.(28) and depends on the accelerating field $\mathrm{E}_{\text {acc }}$. This in turn depends on the transit-time factor $T(\beta)$ which is a function of the cell geometry, and of the beam velocity $\beta$. Since all the cavity cells in the linac structure have been adjusted to the same length $l_{c}$, denoting with $E_{0}$ the actual axial field in a given cell,

$\mathrm{E}_{\mathrm{acc}}=\mathrm{E}_{\mathrm{a}} \mathrm{T}(\beta) / \mathrm{T}\left(\beta_{0}\right)$

where

$\mathrm{E}_{\mathrm{a}}=\mathrm{E}_{0} \mathrm{~T}\left(\beta_{0}\right)$

For half-wavelength cavity-cells the optimum cell length should be adjusted to

$l_{\mathrm{c}}=\lambda \beta_{0} / 2$

where $\lambda$ is the accelerating field wavelength. Otherwise the transit-time factor

$\mathrm{T}(\beta)=\mathrm{H}(\mathrm{a}) \mathrm{F}_{N}\left(\beta, \beta_{0}\right) \sin \left(\pi l_{\mathrm{c}} / \beta \lambda\right) /\left(\pi l_{\mathrm{c}} / \beta \lambda\right)$

where

$\begin{array}{rlll}\mathrm{F}_{N}\left(\beta, \beta_{0}\right) & =(-1)^{(N-1) / 2} \cos \left(N \pi \beta_{0} / 2 \beta\right) / N \cos \left(\pi \beta_{0} / 2 \beta\right) & \text { for } N \text {, odd } \\ & =(-1)^{N / 2+1} \sin \left(N \pi \beta_{0} / 2 \beta\right) / N \cos \left(\pi \beta_{0} / 2 \beta\right) & \text { for } N \text {, even }\end{array}$

is a form factor which gives the energy gain of a proton with velocity $\beta$ traversing a cavity made of $N$ cells of length given by $\mathrm{Eq}$. (34). These form factors are unit for $\beta=\beta_{0}$. Finally, 


$$
\mathrm{H}(\mathrm{a})=1 / \mathrm{I}_{0}\left(2 \pi a / \beta_{0} \gamma_{0} \lambda\right)
$$

is a cavity-aperture factor for radial aperture $a$, and $\mathrm{I}_{0}$ is the modified Bessel function. For an assigned amount of of power in the couplers, as the beam velocity varies from a period to the next, the transit-time factor $T(\beta)$ will vary also, and the axial field $E_{0}$ will then be adjusted accordingly so that $\mathrm{E}_{\mathrm{acc}}$ is constant with a value given by combining Eq.s (28, 31,33 and 34).

The power dissipated on the cavity walls per cryo-module is

$$
\mathrm{P}_{\mathrm{w}}=N M l_{\mathrm{c}} \mathrm{E}_{0}{ }^{2} / \mathrm{R}_{\mathrm{s}}=N M l_{\mathrm{c}} \mathrm{E}_{\mathrm{a}}{ }^{2} / \mathrm{Z}_{0} \mathrm{~T}_{0}{ }^{2} \mathrm{Q}_{0}
$$

where $T_{0}=T\left(\beta_{0}\right), R_{S}=Z_{0} Q_{0}$ is the shunt impedance per unit of length, $Z_{0}$ is the cavity characteristic impedance, also per unit of length, and $\mathrm{Q}_{0}$ the unloaded figure of merit. Depending on the choice of the cell length $l_{c}$ and of the reference value $\beta_{0}$, typical values of $Z_{0} T_{0}{ }^{2}$ are in the range of few hundred ohm $/ \mathrm{m}$. The figure of merit $\mathrm{Q}_{0}$ can be estimated from the formula

$\mathrm{Q}_{0}=10^{9} \mathrm{G} / \mathrm{R}_{\mathrm{w}}$

where $G$ is a cell geometry factor of a value around $250 \beta_{0}$, and $R_{w}$ is the surface impedance, given in nohm,

$\mathrm{R}_{\mathrm{w}}=\mathrm{R}_{\mathrm{res}}+(0.1 \mathrm{nohm}) \mathrm{f}_{\mathrm{rf}}^{2} \exp \left(-18 / \mathrm{T}_{\mathrm{k}}\right) / \mathrm{T}_{\mathrm{k}}$,

where $R_{\text {res }}$ is the residual impedance with a value of about 20 nohm, $T_{k}$ is the environment temperature in degrees Kelvin, and $\mathrm{f}_{\mathrm{rf}}$ is the if frequency in $\mathrm{MHz}$.

The power dissipated to the high-order modes of the cavity in one cryo-module can be estimated from the equation

$\mathrm{P}_{\mathrm{HOM}}=\left(1.7 \times 10^{-6}\right.$ Watt $) N M \mathrm{f}_{\mathrm{rf}} \mathrm{I}_{\mathrm{b}}{ }^{2}$,

where $\mathrm{f}_{\mathrm{rf}}$ is in $\mathrm{MHz}$ and the average beam current $I_{\mathrm{b}}$ in $\mathrm{mA}$.

Note that, whereas the power $\mathrm{P}_{\mathrm{HOM}}$ dissipated to the high-order modes is constant, the wall-dissipated power $\mathrm{P}_{\mathrm{W}}$ varies from period to period.

The AC power requirements to operate the complete rf system depends on the RF-to-AC efficiency

$\mathrm{P}_{\mathrm{AC}}=\mathrm{P}_{\mathrm{ri}} / \eta_{\mathrm{rf}}$,

where $P_{\mathrm{rf}}$ is given by Eq. (30). For high-power Klystrons typically $\eta_{\mathrm{rf}} \sim 0.585$, and for lowerpower Klystrodes $\eta_{\mathrm{rf}} \sim 0.7$. These figures include dissipation in the rf waveguides $(\sim 5 \%)$ and DC-to-AC conversion efficiency ( $~ 99 \%)$. 


\section{Cryogenic Power Considerations}

The total cryogenic power per cryo-module that is required in a superconducting linac for protons is made of three contributions

$P_{\text {cryo }}=\quad P_{w}+P_{\text {HOM }}+P_{s}$,

where the power $\mathrm{P}_{\mathrm{w}}$ dissipated on the cavity walls and the power $\mathrm{P}_{\mathrm{HOM}}$ dissipated to the highorder modes are already given, respectively, by Eq.s ( 39 and 42 ). The last contribution $P_{s}$ is the static loss which is dissipated through the walls of the cryostat

$\mathrm{P}_{\mathrm{s}}=\mathrm{W}_{\text {cryo }} l_{\text {cryo }}$,

where typically $\mathrm{W}_{\text {cryo }}=5 \mathrm{~W} / \mathrm{m}$.

The AC power requirement depends on the conversion efficiency which, unfortunately, for cryogenic systems is quite low. It depends also on the final required temperature.

$\mathrm{P}_{\mathrm{AC}}=\mathrm{P}_{\text {cryo }} / \eta_{\text {cryo }}$

For an environment around $4.2^{\circ} \mathrm{K}$, one can expect $\eta_{\text {cryo }} \sim 0.004$.

\section{Pulsed Superconducting Linacs}

For the continuous mode of operation of a superconducting linac for protons, average and peak values are equal. This is not so for a pulsed mode of operation. In this case one defines a repetition rate $\mathrm{f}_{\text {rep}}$, a pulse length $\mathrm{T}_{\mathrm{p}}$, and a duty cycle

$\delta=\mathrm{T}_{\mathrm{p}} \mathrm{f}_{\mathrm{rep}}$,

which is the liraction of the total time when beam is present and accelerated. In this case, average and peak values, like beam current, rf power and so on, differ from each other. If all the accelerator and beam parameters defined above refer to peak values, the corresponding average values can be denoted within brackets, and in principle can be simply derived after multiplying the peak values with the duty cycle. There is one difference, that is, just before the beam is injected into the linac for acceleration, the if cavities are to be refilled with of energy. This takes an amount of time $T_{F}$ which has the effect of lengthening the duty cycle so that the total running time is $T_{p}+T_{F}$ Since the beam is present only during the period of length $T_{p}$, the average values are

$$
\begin{aligned}
& <\mathrm{I}_{\mathrm{h}}>=\delta q \mathrm{I}_{\mathrm{b}} \\
& <\mathrm{P}_{\mathrm{rf}}>=\delta\left(q \mathrm{P}_{\mathrm{h}}+\mathrm{P}_{\mathrm{w}}\right)\left(1+\mathrm{T}_{\mathrm{F}} / \mathrm{T}_{\mathrm{p}}\right)+\delta q \mathrm{P}_{\mathrm{IIOM}} \\
& \left\langle\mathrm{P}_{\text {cryo }}>=\delta \mathrm{P}_{\mathrm{w}}\left(1+\mathrm{T}_{\mathrm{F}} / \mathrm{T}_{\mathrm{p}}\right)+\delta q \mathrm{P}_{\mathrm{IIOM}}+\mathrm{P}_{\mathrm{s}}\right.
\end{aligned}
$$


In Eq.(48), $I_{\mathrm{b}}$ actually denotes the proton beam peak current, and $q(\sim 60 \%)$ is a chopping ratio, typically at frequencies around the $\mathrm{MHz}$ value, as it may be in the case when the beam is to be injected in a ring. The filling time $T_{F}$ is given by

$\mathrm{T}_{\mathrm{F}}=1.4\left(\mathrm{Q}_{0} / \omega\right) /\left(2+\mathrm{P}_{\mathrm{b}} / \mathrm{P}_{\mathrm{w}}\right)$

Pulsing a superconducting linac has of course several technical implications. The rf pulsing is performed by modulators or circulators, which are electronic components with difficulties that depend on the choice of frequency, pulse duration, repetition rate, and the excursion of rf power. Moreover, Klystrons may be significantly less efficient $\left(\eta_{\mathrm{rf}} \sim 0.45\right)$, since the cathode voltage has to be lowered. Finally, there are problems associated with frequency detuning caused by the Lorentz forces and microphonics. In principle, though, all these problems can be tackled and resolved.

\section{Transverse Beam Confinement}

The transverse motion of protons is confined with quadrupole magnets located in the insertions between cryo-modules. There are two possible arrangements: FODO and doublets. The first has a single quadrupole per insertion with alternating polarity from one insertion to the next. The second arrangement is made of a sequence of pairs of quadrupoles (doublets), of opposite polarity, per insertion. The gradient $B^{\prime}$ of quadrupoles varies with the beam energy, that is the magnetic rigidity $\mathrm{B} \rho$, so that the focussing parameter $\mathrm{k}=\mathrm{B}^{\prime} / \mathrm{B} \rho$ is constant. This will ensure continuous matching of the transverse motion.

Denoting with $\varepsilon_{\mathrm{n}}$ the normalized betatron emittance of the beam (for instance, the rms value), the rms beam radius at a quadrupole location where the amplitude function has the largest value $\beta_{Q}$ is

$$
b=\left(\varepsilon_{\mathrm{n}} \beta_{\mathrm{Q}} / \pi \beta \gamma\right)^{1 / 2} .
$$

Denoting with $\psi$ the betatron phase advance per period of length $L_{\mathrm{p}}=l_{\text {cryo }}+l_{\text {ins }}$, in the case of the FODO arrangement, using the thin-lens approximation,

$$
\begin{aligned}
& \beta_{\mathrm{Q}}=\left(L_{\mathrm{p}} / \sin \psi\right)[(1+\sin \psi) /(1-\sin \psi)]^{1 / 2}, \\
& \mathrm{k} l_{\mathrm{Q}}=(2 \sin \psi) / L_{\mathrm{p}} .
\end{aligned}
$$

where $l_{\mathrm{Q}}$ is the quadrupole length. Whereas for the doublet arrangement,

$$
\begin{aligned}
& \beta_{\mathrm{Q}}=\left\{L_{\mathrm{p}}+2\left[d_{\mathrm{Q}}\left(L_{\mathrm{p}}-d_{\mathrm{Q}}\right)\right]^{1 / 2} \sin (\psi / 2)\right\} / \sin \psi, \\
& \mathrm{k} l_{\mathrm{Q}}=2 \sin (\psi / 2) /\left[d_{\mathrm{Q}}\left(L_{\mathrm{p}}-d_{\mathrm{Q}}\right)\right]^{1 / 2} .
\end{aligned}
$$

where $d_{\mathrm{Q}}$ is the space between the quadrupoles of the same doublet. If $a$ denotes the inner radius 'of the cavities, assuming it is equal to that of the vacuum chamber in the insertions and elsewhere, one desires that the ratio $a / b$ is maintained at a large value $(>20)$ to avoid latent activation 
effects that may be caused by uncontrolled beam losses. The FODO arrangement takes less space, and requires less field gradient, but the doublet arrangement would give the smallest beam size overall.

\section{General guidance for the cost estimate of a superconducting linac}

In order to make comparisons of different linac designs, and to allow analysis of trading between cost and performance, it is useful, at the design stage, to have some guidance on the estimating of the cost of a superconducting linac. The following are simple parametric estimates which are to be taken with caution; they provide only an indication of the behavior of the overall cost, and should be followed by a more-detailed engineering cost estimate, once all the accelerator components have been identified.

There are two contributions to the overall cost: Capital (direct) Cost needed for the construction proper of the accelerator, and Operation Cost. The Capital Cost can be broken down in the following major components:

Insertion (assuming normal conducting)

including vacuum chamber with flanges and bellows, quadrupole magnets, steering dipoles and beam position monitors

vacuum port, and vacuum pump

$100 \mathrm{k} \$ / \mathrm{m}$

Superconducting.structure

including cryostats with feed-throughs, internal refrigeration

rf cavities and vacuum chamber

$300 \mathrm{k} \$ / \mathrm{m}$

Tunnel, with service buildings

$70 \mathrm{k} \$ / \mathrm{m}$

Refrigeration Plant with piping

$2 \mathrm{k} \$ / \mathrm{W} @ 4.2^{\circ} \mathrm{K}$

Electrical Distribution

$0.14 \$ / \mathrm{W}$ of $\mathrm{AC}$ power

RF Power, including

Klystrons (assuming 2 Cavities per Klystron)

rf Couplers, waveguides, rf windows

(assuming 1 rf Coupler per Cavity)

Power distribution

CW-Mode

Pulsed-Mode

$1.68 \$ / \mathrm{W}$ of rf power

$2.50 \$ / \mathrm{W}$ of rf power

The Operation Cost depends on the availability ( $75 \%$ ) required over one-year period of the accelerator, and is eventually given as the cost for one-year operation as well as the cumulative cost over a longer period of time ( $\sim 10$ years ). Most of the cost is the electricity bill which can be 
estimated as $0.05 \$ / \mathrm{kWh}$ of total $\mathrm{AC}$ power, which is an average of the electricity cost across the United States. We are not including here cost for maintenance, replacement material, and labor for operation.

The linear accelerator can also be rated with an efficiency parameter: the ratio of average the beam power to the total required $\mathrm{AC}$ power.

\section{An Example of Spallation Neutron Source}

The following is an example of a $2.4-\mathrm{GeV}$ superconducting linac which can be used as a Spallation Neutron Source. One can conceive three modes of operation, shown also in Figure 5:

Continuous Wave (CW) of protons with the average beam power of $60 \mathrm{MW}$ and an average accelerated beam current of $25 \mathrm{~mA}$. A continuous positive-ion source of 30 $\mathrm{mA}$ is required for this mode of operation. No beam chopping is needed.

Long Pulses (LP) of protons in the millisecond range. The linac is operated at either 10 or 60 pulses per second with a duty cycle of 1 to $10 \%$. A 30-mA positive-ion source is still required which can be pulsed accordingly, but no beam chopping is needed. The average beam power ranges between 1 and $6 \mathrm{MW}$ depending on the pulse length and on the repetition rate. The linac needs to be pulsed.

Short Pulses (SP) of microsecond duration of protons. This can be obtained only by injecting the beam, in many turns, in one Compressor Ring, with a negative-ion source, and the charge-exchange injection method, for a more efficient transfer of the beam into the Ring. Moreover, the beam will have to be pre-chopped by about $60 \%$. Expected average beam power will range between 1 and $5 \mathrm{MW}$, depending on the linac pulse length and on repetition rate.

The Linac itself is made of four sections. The first section includes the ion source, two RFQs for acceleration to $5 \mathrm{MeV}$, and a conventional, normal-conducting Drift Tube Linac for acceleration to $100 \mathrm{MeV}$. The front-end section operates at the frequency of $350 \mathrm{MHz}$, and the DTL at 700 $\mathrm{MHz}$, to allow funneling of two ion beams, if it is required in the future. The superconducting linac is made of the three following sections, all operating at $700 \mathrm{MHz}$. The first section accelerates from 100 to $300 \mathrm{MeV}$, the second from 0.3 to $1.2 \mathrm{GeV}$, and the last section from $1.2 \mathrm{to} .2 .4$ $\mathrm{GeV}$. The division in sections allows ranges of beam velocity $\beta$ sufficiently narrow that one can operate them with constant cryo-module configuration without too much loss of accelerating gradient, because of the reduced transit-time factors. In each of the three superconducting sections the cavity-cell length $l_{\mathrm{c}}$ is adjusted to yield the optimum transit-time factor at an intermediate $\beta$ value. The major parameters of the superconducting Linac are shown in Table 1 , and those for each of the three sections in Table 2. The cavity filling times $T_{F}$ are shown in Figure 15.

For the Long-Pulse mode of operation, the average available beam power and the average required rf power can be expressed as functions of the beam pulse length $T_{p}$ and the repetition rate $\mathrm{f}_{\text {rep }}$. The summary is given in Figures 16 and 17 , where the required average total AC power 


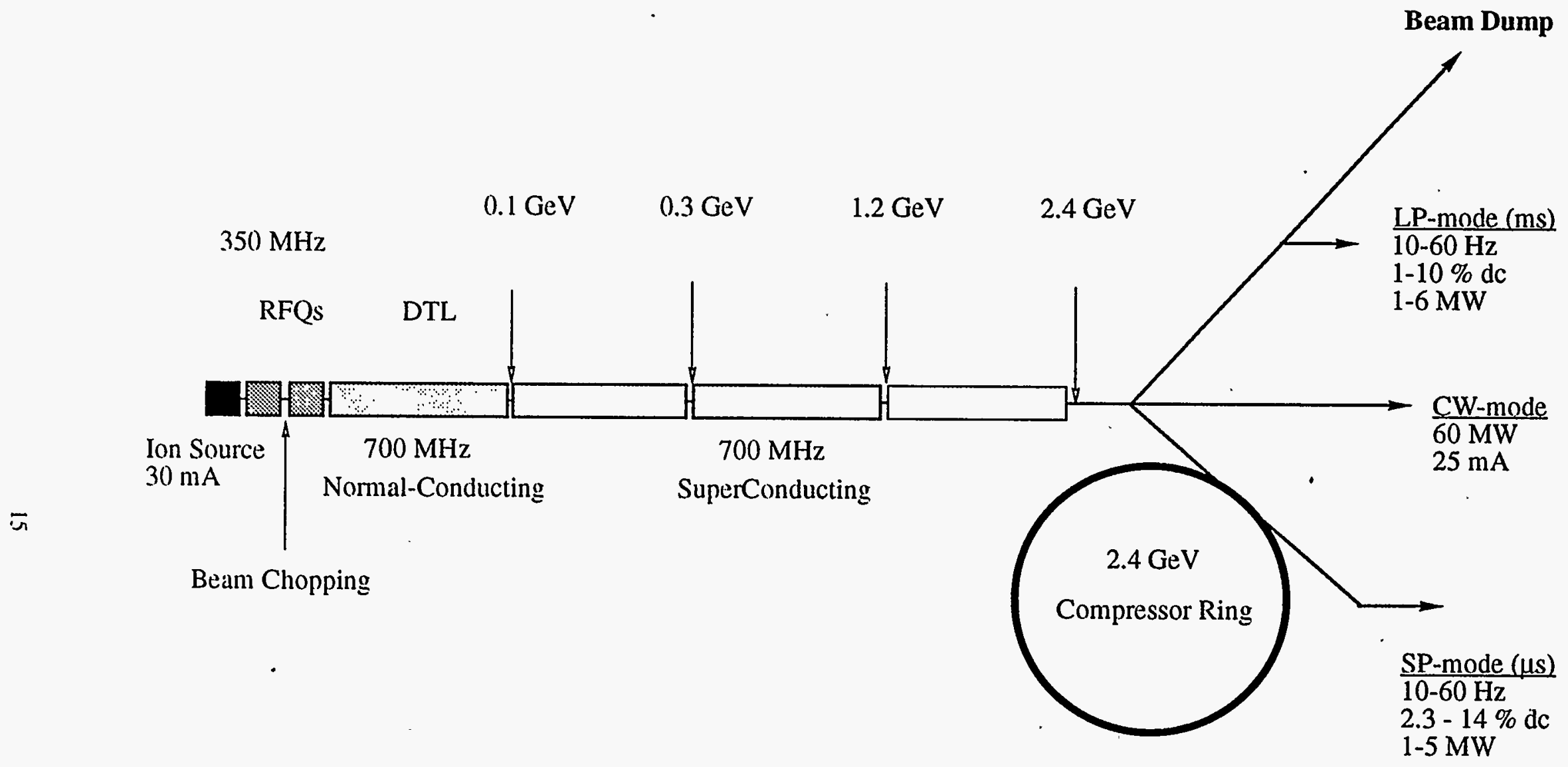

Figure 5. Layout of the Spallation Neutron Source using a $2.4 \mathrm{GeV}$ Superconducting proton Linac 
Table 1. General Parameters of the 2.4-GeV Superconducting Linac

$\begin{array}{lr}\text { Total Beam Power (CW) } & 60 \mathrm{MW} \\ \text { Beam Current, } I_{\mathrm{b}} & 25 \mathrm{~mA} \\ \text { Ion Source Current } & 30 \mathrm{~mA} \\ \text { Initial Kinetic Energy } & 100 \mathrm{MeV} \\ \text { Final Kinetic Energy } & 2.4 \mathrm{GeV} \\ \text { Frequency } & 700 \mathrm{MHz} \\ \text { No. of Protons / Bunch . } & 4.5 \times 10^{8} \\ \text { Temperature } & 4.2^{\circ} \mathrm{K} \\ & \\ \text { Cells / Cavity, } N & 4 \\ \text { Cavity Separation, } d & 32 \mathrm{~cm} \\ \text { Cold-Warm Transition, } l_{\mathrm{w}} & 30 \mathrm{~cm} \\ & \\ \text { Accelerating Gradient, E } & \\ \text { Cavities / Klystron } & 7.302 \mathrm{MeV} / \mathrm{m} \\ \text { No. of rf Couplers / Cavity, } \mathrm{n}_{\mathrm{c}} \text { coup } & 2 \\ & 1 \\ \text { RF Phase Angle } & -30^{\circ} \\ \text { Method for Transverse Focussing } & \mathrm{FODO} \\ \text { Betatron Phase Advance / FODO cell } & 90^{\circ} \\ \text { Normalized rms Emittance } & \\ \text { rms Bunch Area } & 0.29 \pi \mathrm{mm} \mathrm{mrad} \\ \end{array}$

is also shown, together to the capital and operation cost, versus the beam pulse length.

Beam pulses of shorter lengths, around a microsecond, can be obtained only with a negative-ion source and by accumulating several beam turns in one Accumulator Ring, where the beam can be compressed to the required length. For this mode of operation, the beam is to be chopped at a ratio $q=60 \%$, at the revolution frequency of the Accumulator Ring. Moreover, the Linac is to be pulsed at a repetition rate which is either 10 or $60 \mathrm{~Hz}$. Assuming a beam peak power of $60 \mathrm{MW}$, an average beam power of $5 \mathrm{MW}$ at the repetition rate of $60 \mathrm{~Hz}$, with a chopping ratio of $60 \%$, requires a pulse length of $2.315 \mathrm{~ms}$. Taking a maximum of 1000 beam turns injected into the Accumulator Ring, one derives $666 \mathrm{~m}$ for the circumference of the Ring. The summary of parameters for the Short-Pulse mode of operation is given in Table 3.

\section{Acknowledgments}

The Author wishes to thank Dominic Chan, and Tom Wangler, of Los Alamos National Laboratory, for the opportunity given to him of doing this work. He also thanks them and Klaus Bongardt of Julich, Germany, for useful discussions on several technical issues described in this report. 
Table 2. Summary of the 2.4-GeV 25-mA Superconducting Linac Design

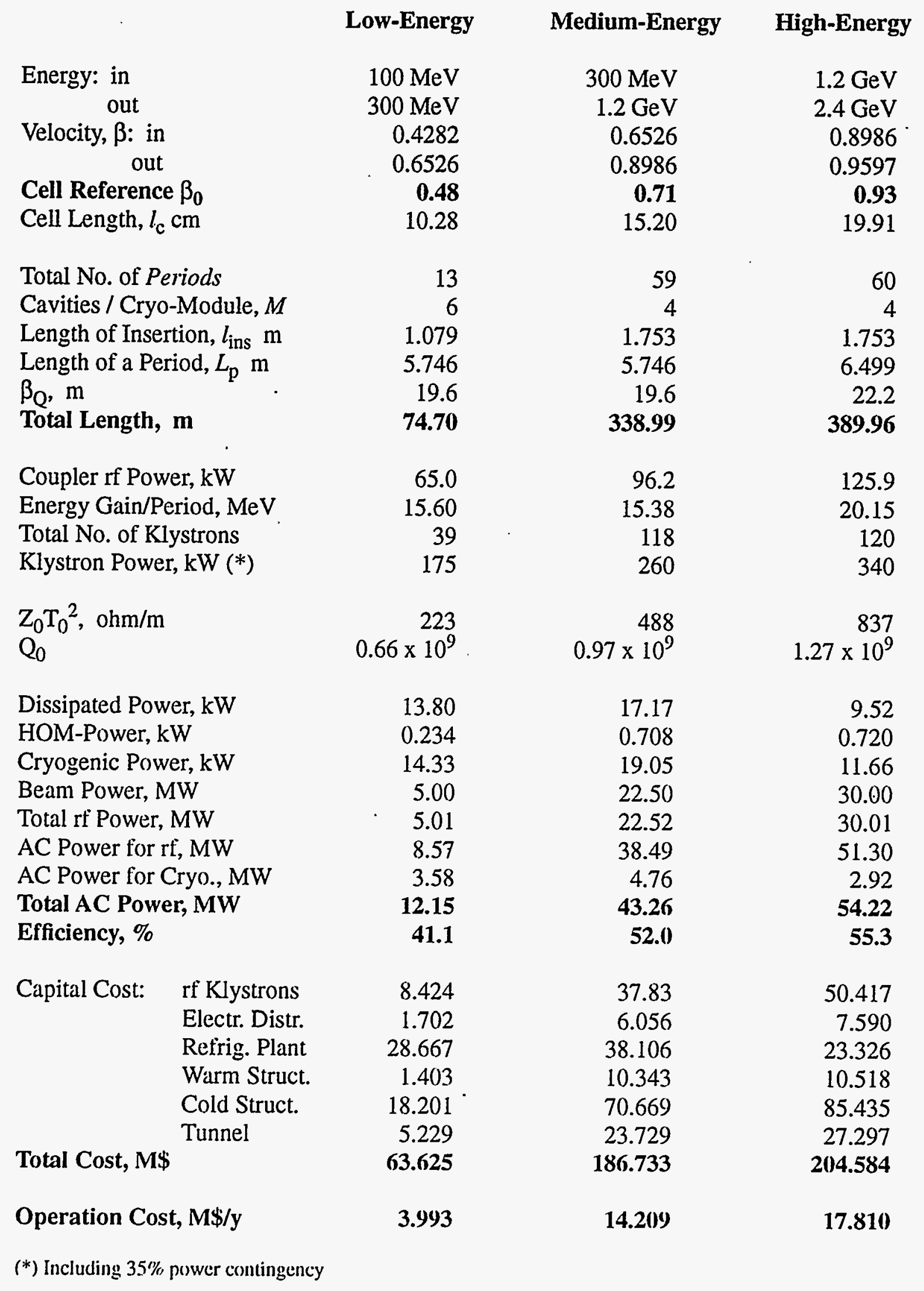




\section{Table 3. Short-Pulse Mode of Operation}

Repetition Rate, $\mathrm{Hz}$

10

60

Pulse Length, ms

2.315

Chopping Ratio, \%

60

Chopping Frequency, $\mathrm{MHz}$

0.432

Duty Cycle, \% .

2.315

Number of Beam Turns injected

Accumulator Ring Circumference, $\mathrm{m}$

Peak Beam Current, mA

Average Beam Current, $\mathrm{mA}$

0.579

Average Beam Power, MW

0.833

Average if Power, MW

0.87

Average Cryogenic Power, kW

3.48

Average total AC Power, MW

2.80

Efficiency, \%

29.75

Capital Cost, $\mathrm{M} \$$

262.350

Operation Cost, M\$/year

0.921

1000

666

25

3.473

5.23

6.34

13.21

37.85

280.425

4.338 

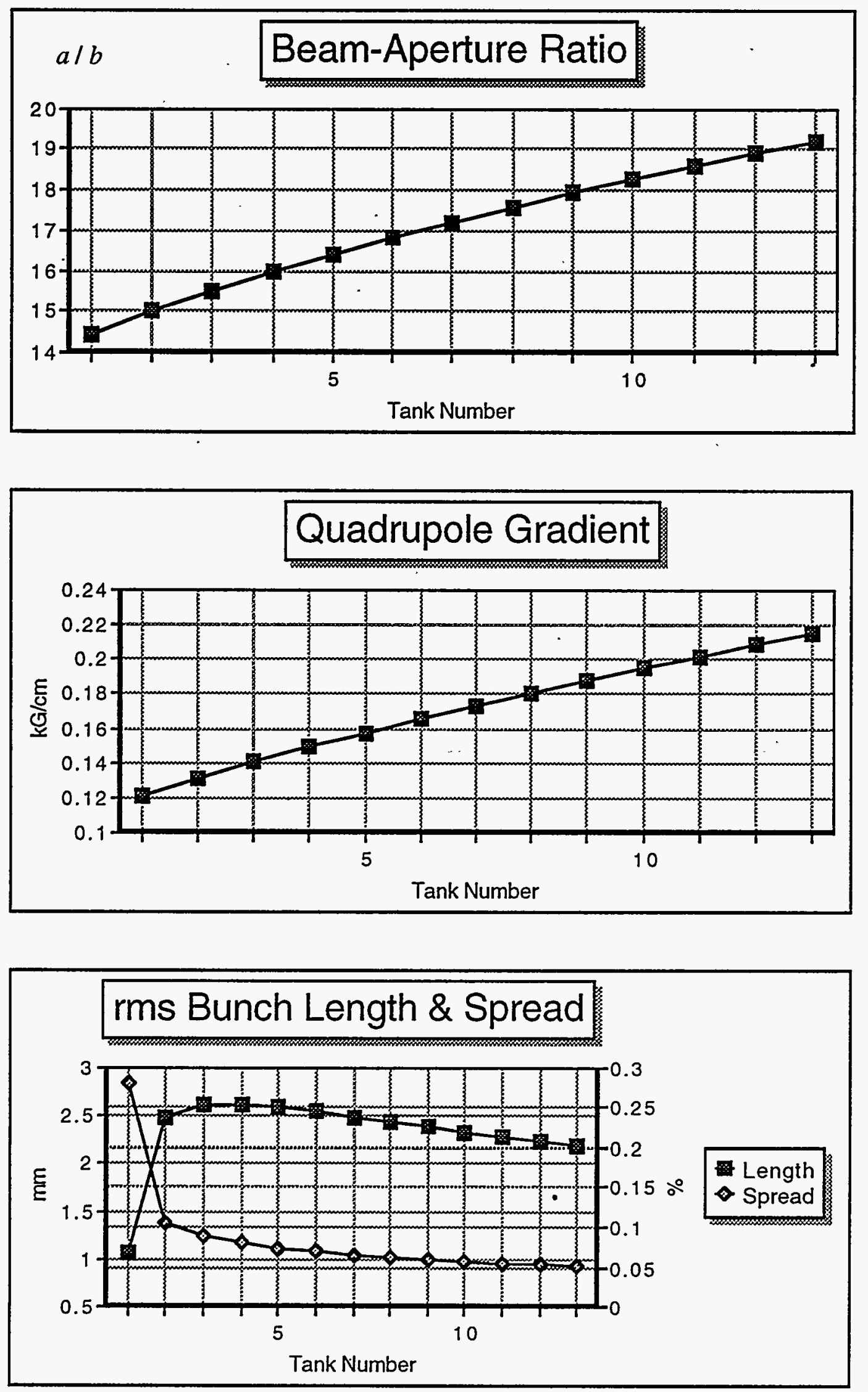

Figure 6. Plots (1) of Behavior versus period (tank) number of the Low-Energy Section 

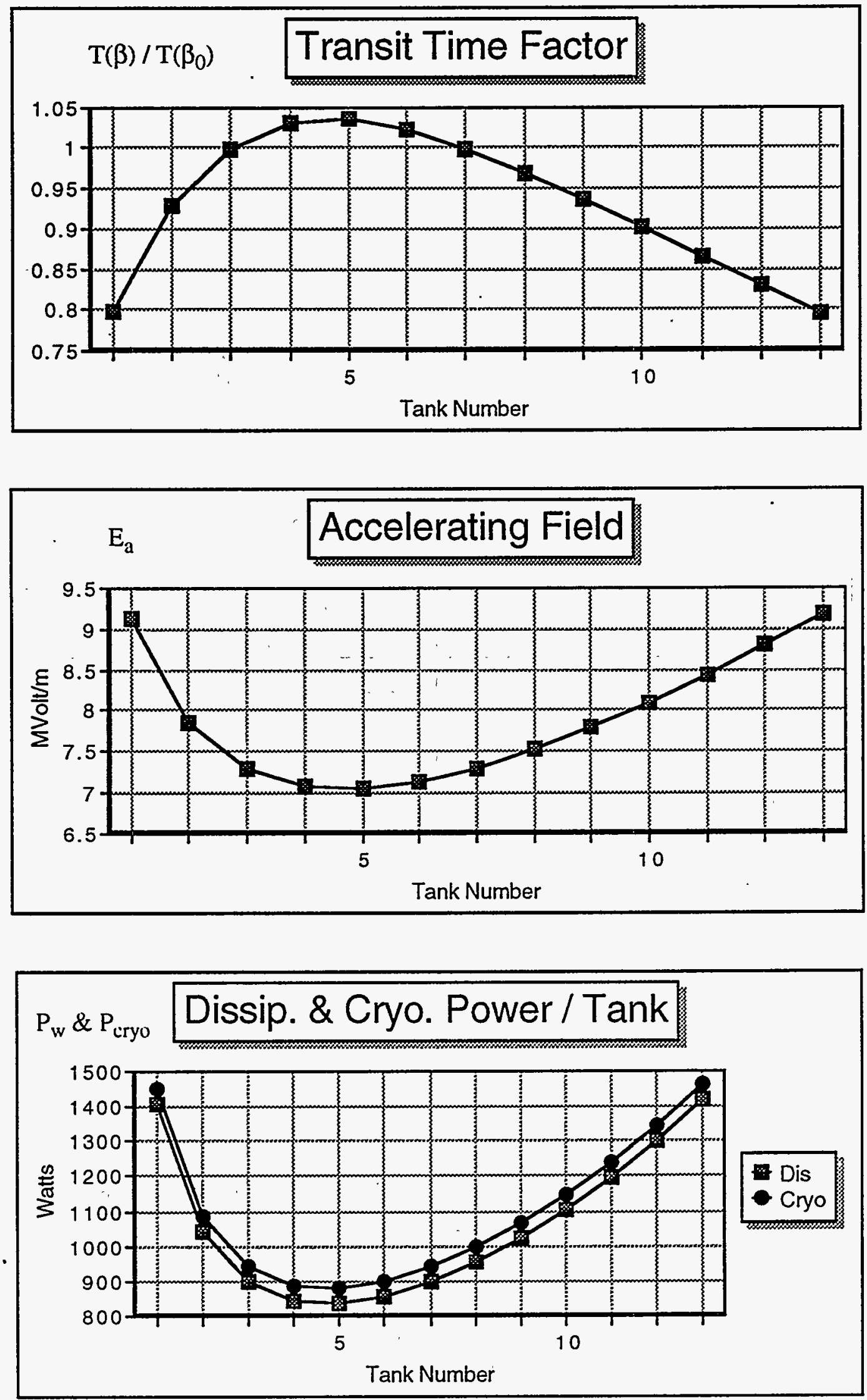

Figure 7. Plots (2) of Behavior versus period (tank) number of the Low-Energy Section 

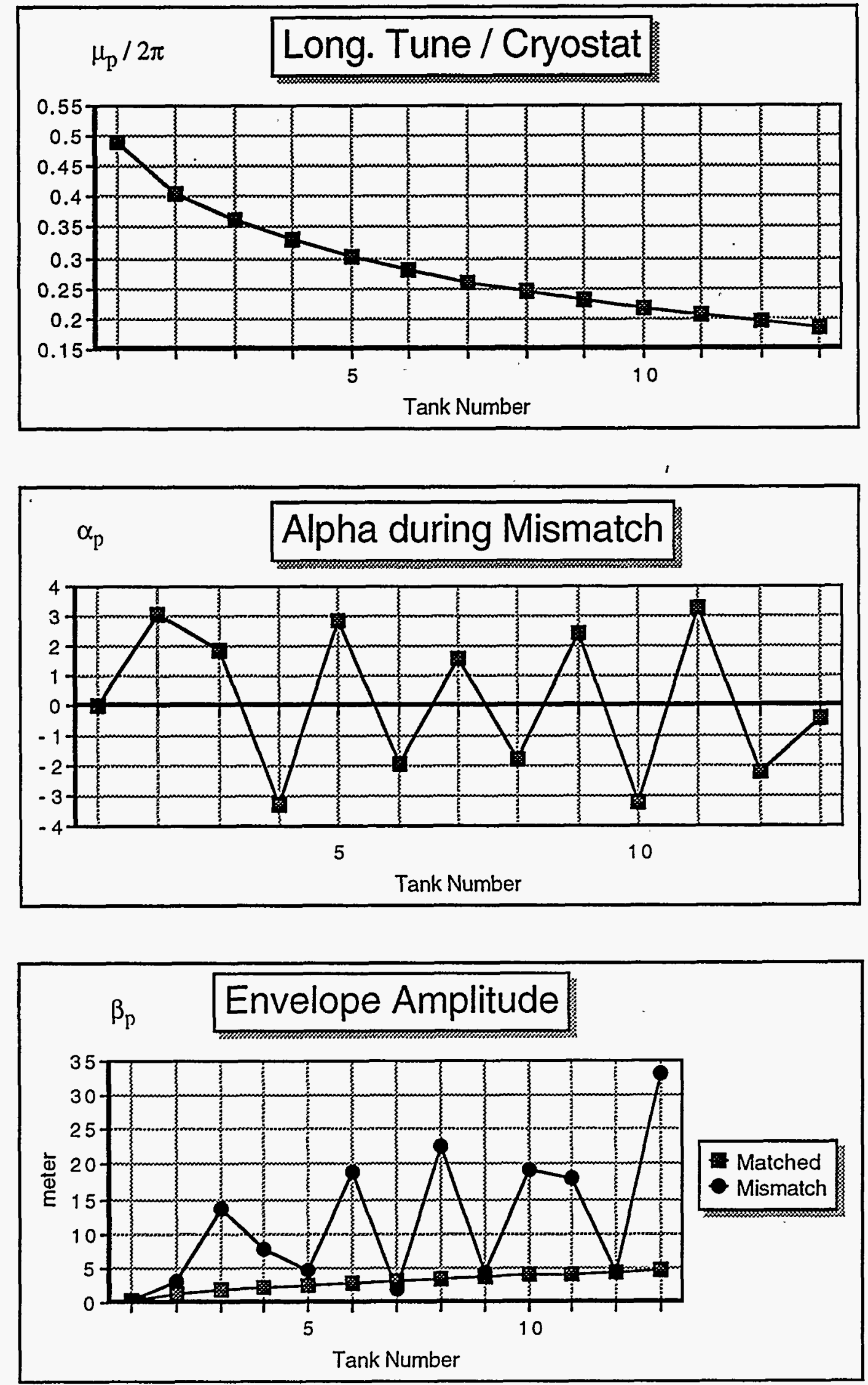

Figure 8. Plots (3) of Behavior versus period (tank) number of the Low-Encrgy Section 

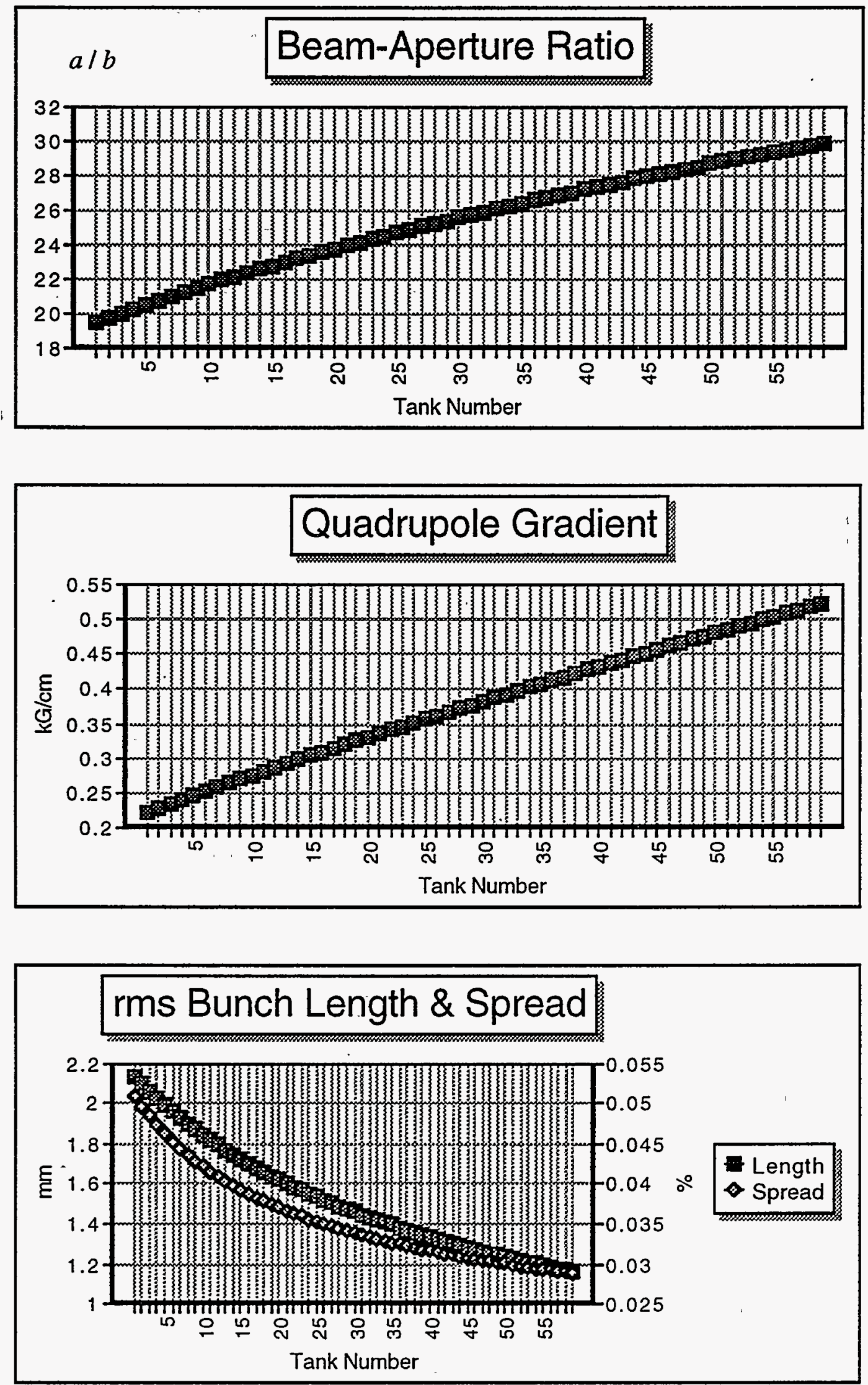

Figure 9. Plots (1) of Behavior versus period (tank) number of the Medium-Energy Section 

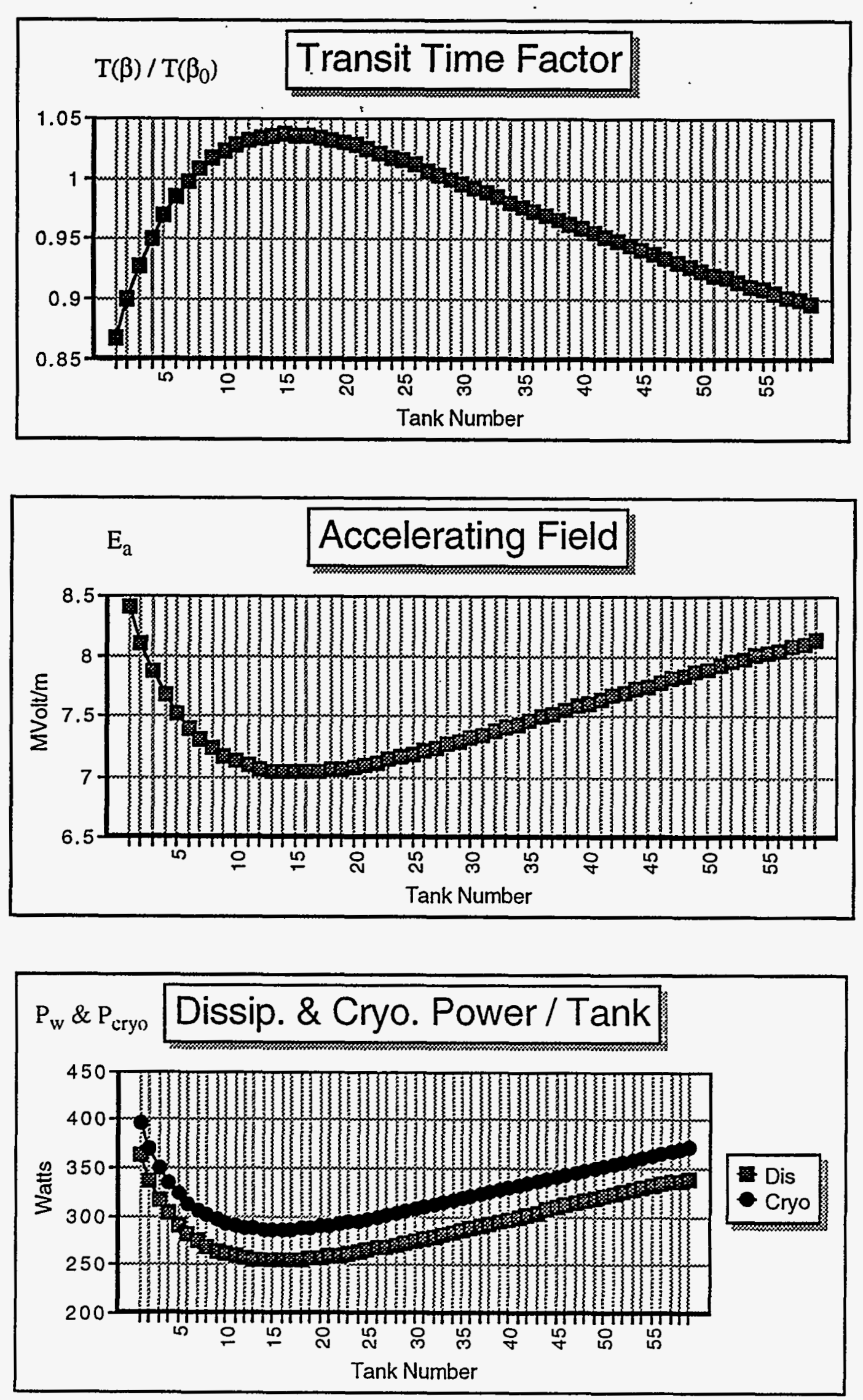

Figure 10. Plots (2) of Behavior versus period (tank) number of the Medium-Energy Section 

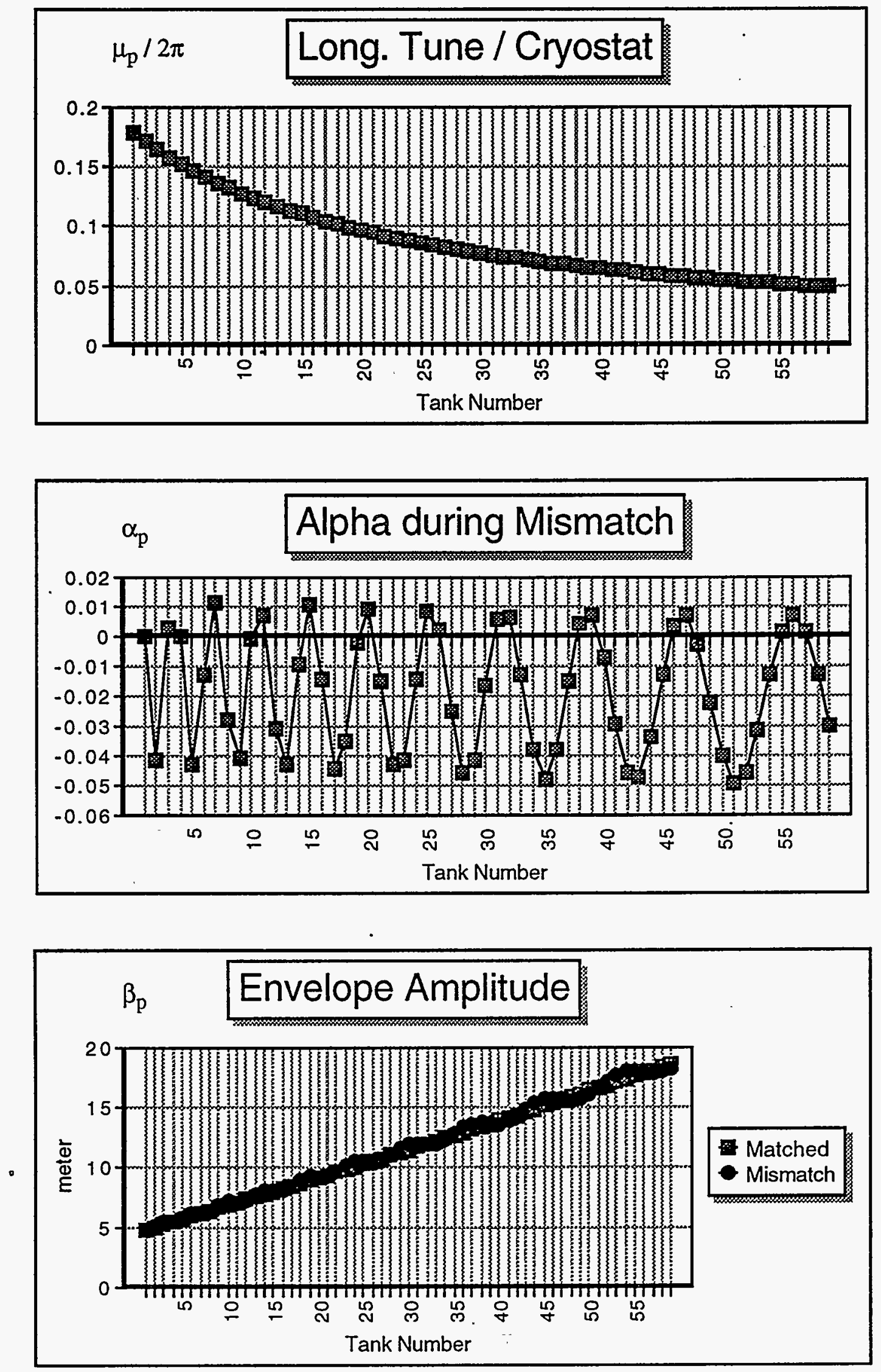

Figure 11. Plots (3) of Behavior versus period (tank) number of the Medium-Energy Section 

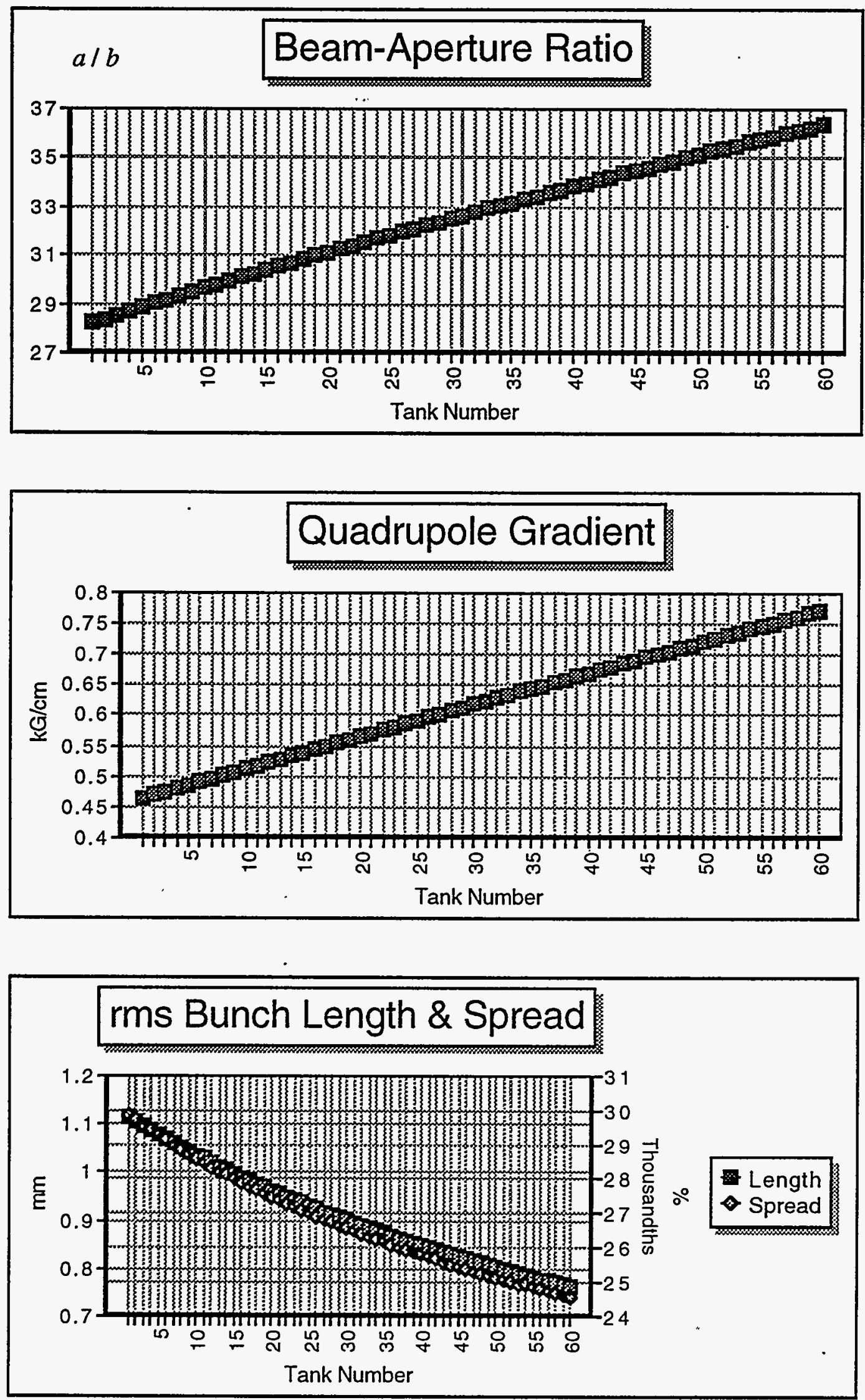

Figure 12. Plots (1) of Behavior versus period (tank) number of the High-Energy Section 

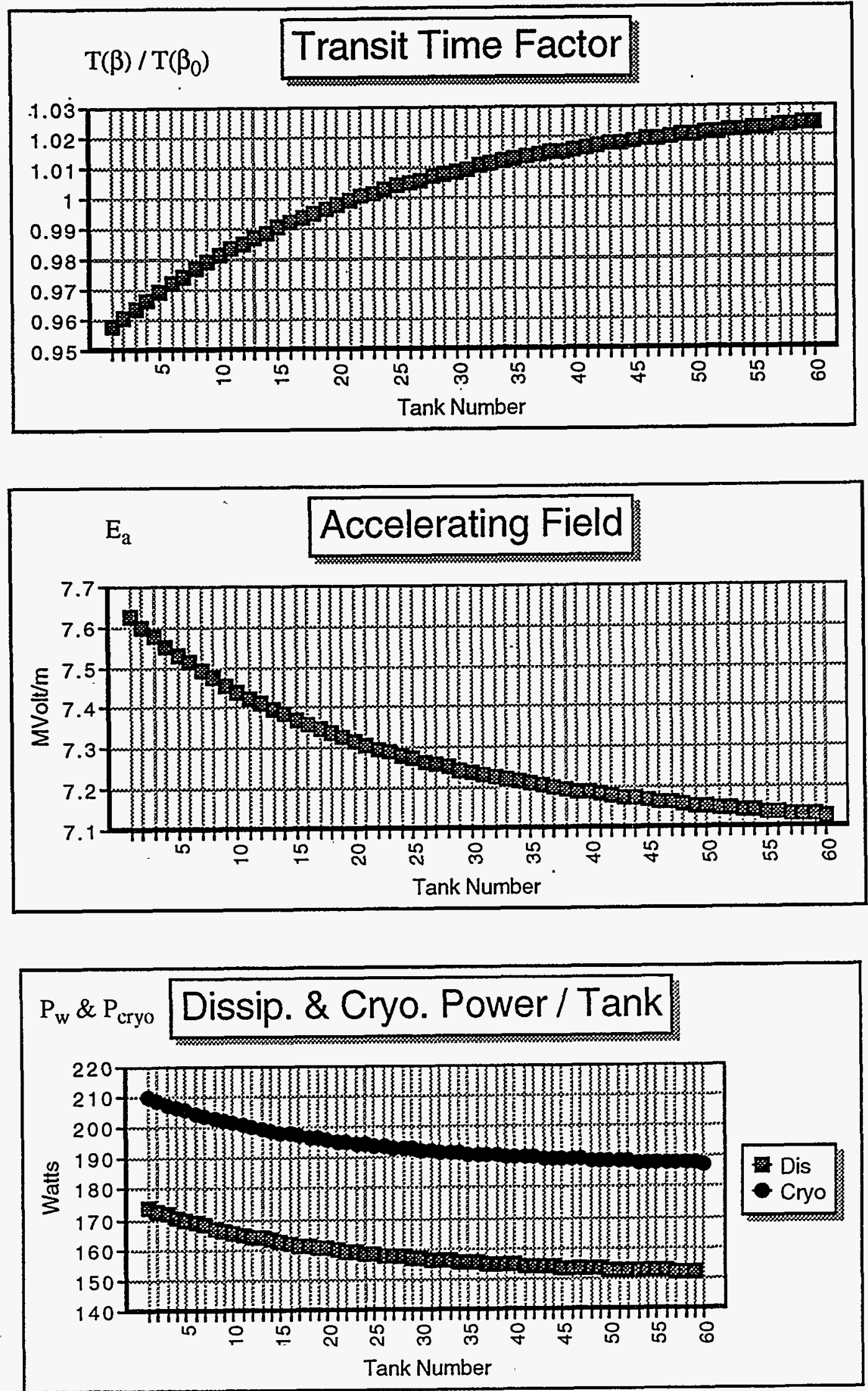

Figure 13. Plots (2) of Behavior versus period (tank) number of the High-Energy Section 

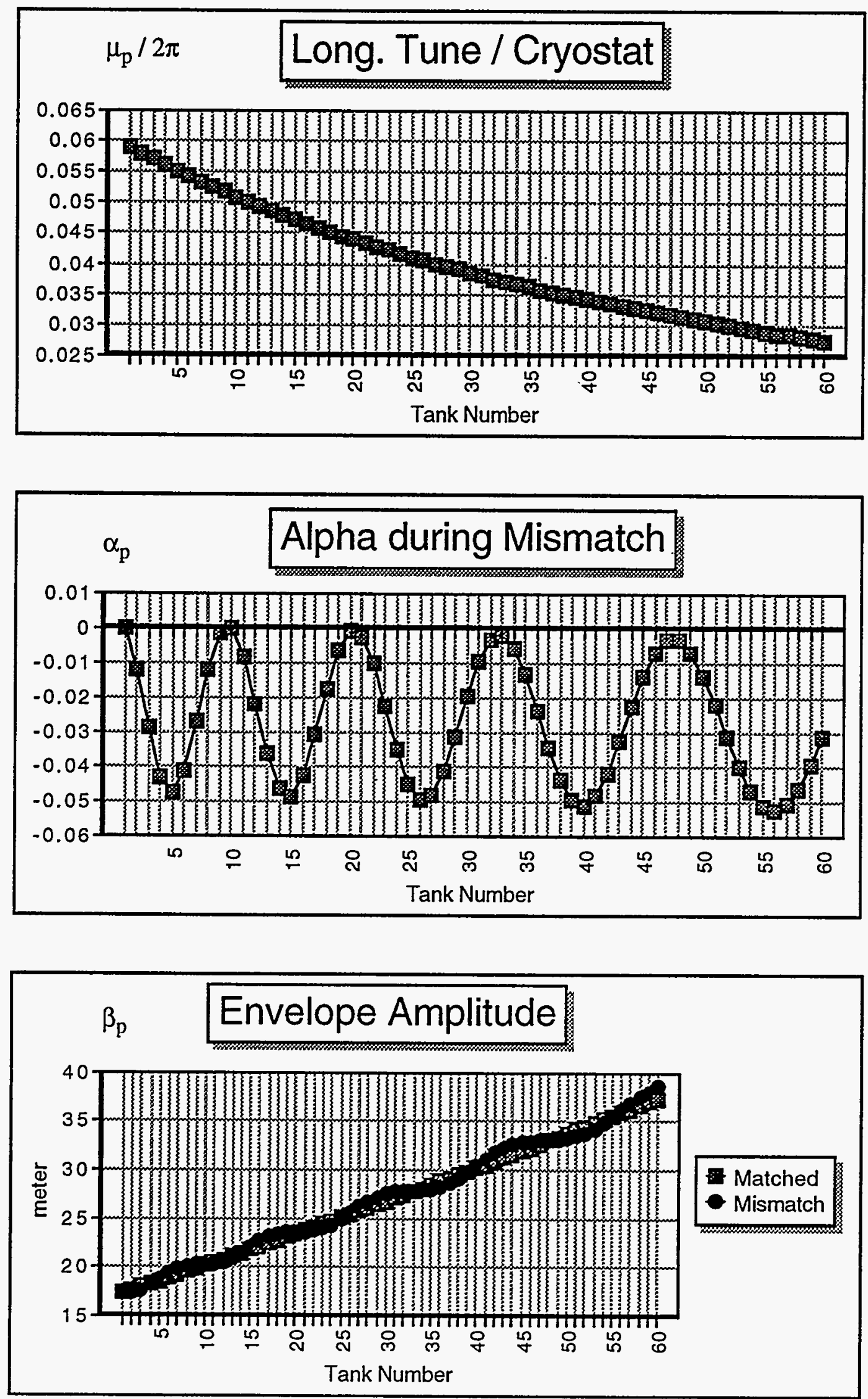

Figure 14. Plots (3) of Behavior versus period (tank) number of the High-Energy Section 

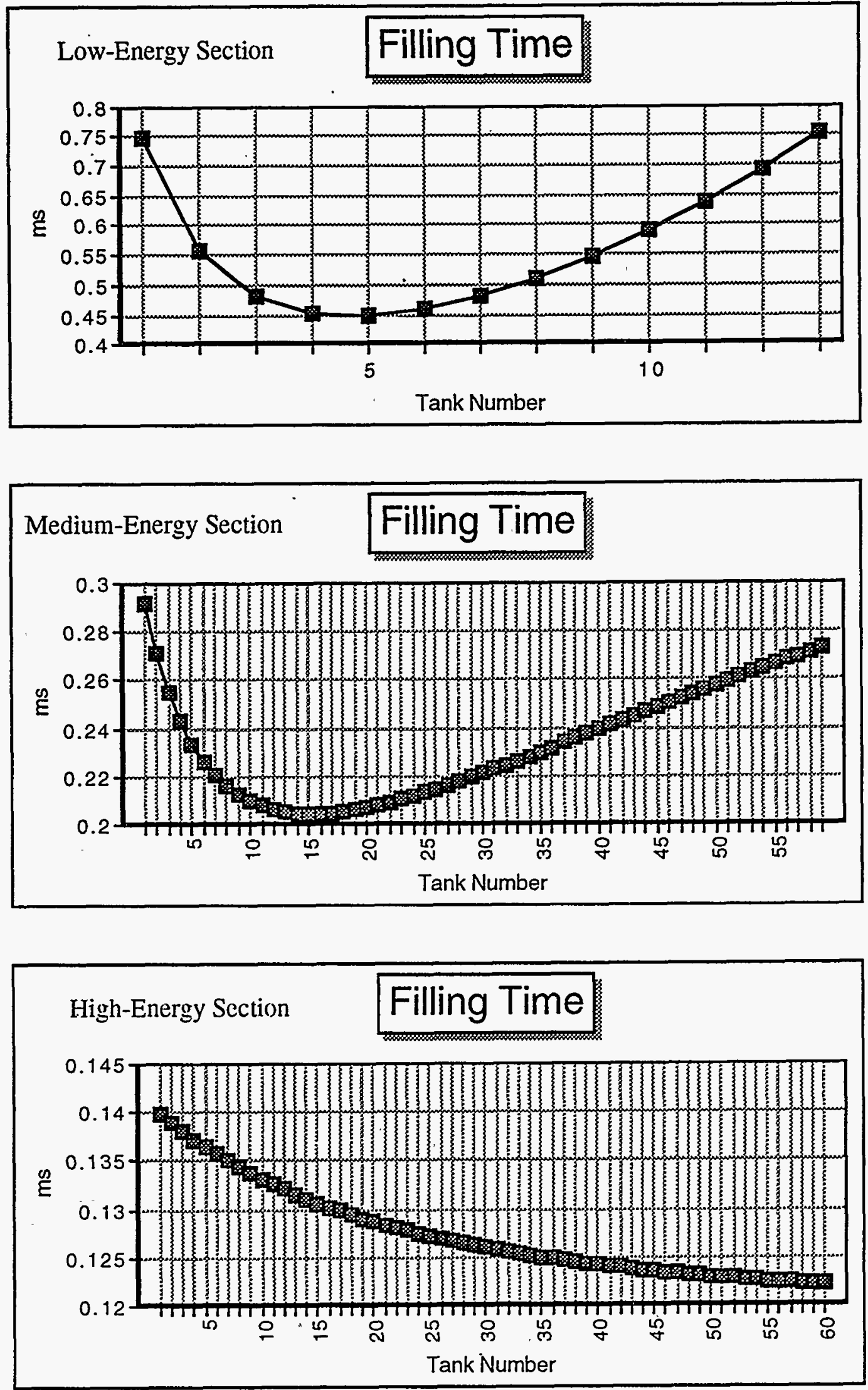

Figure 15. Cavily Filling Time $T_{1}$ : versus period (tank) number for the 3 Linac sections 

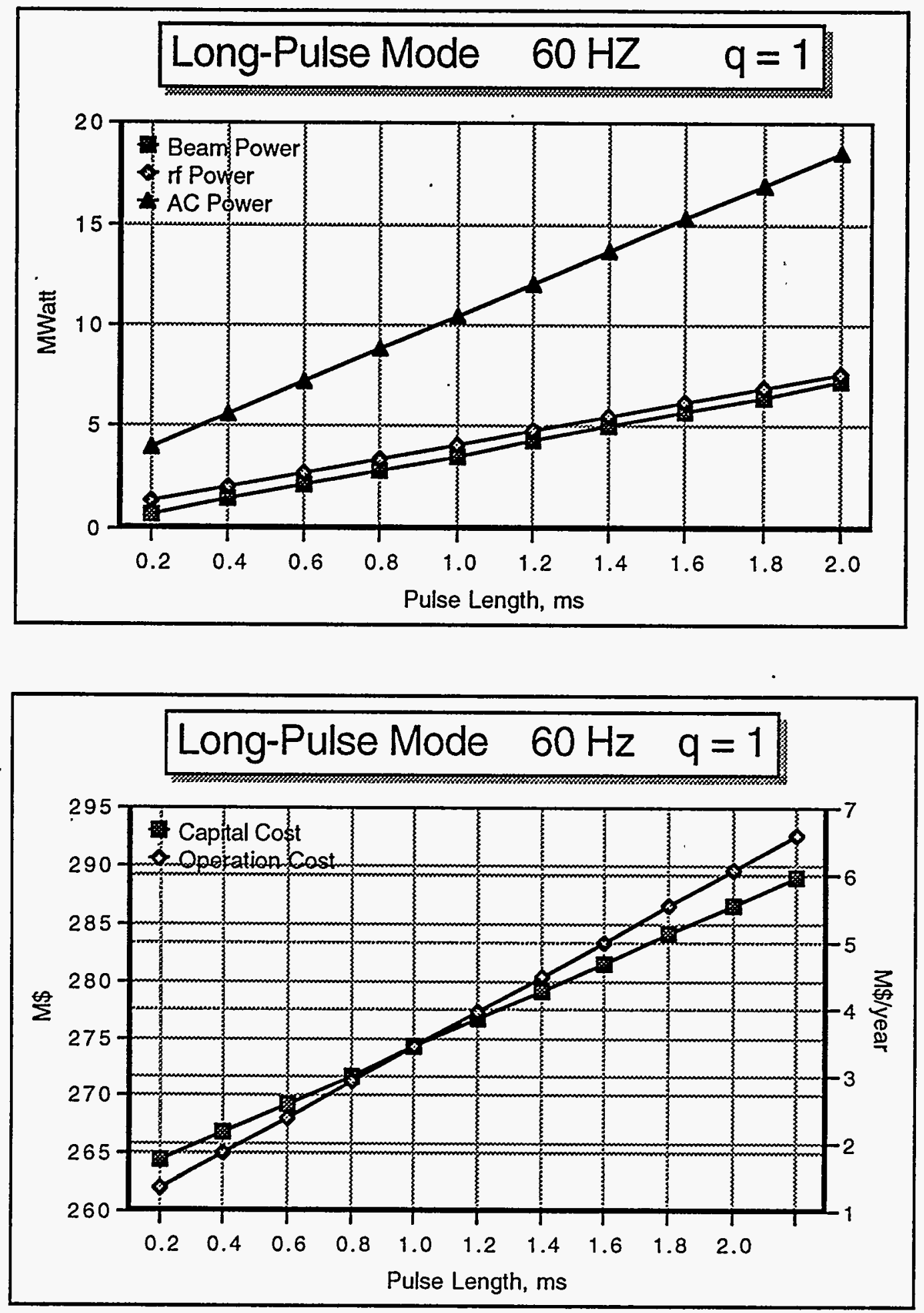

Figure 16. Power and Cost values lor the Long-Pulse mode, unchopped, at $60 \mathrm{~Hz}$ repetition rate, versus beam Pulse Length $\mathrm{T}_{\mathrm{p}}$ 

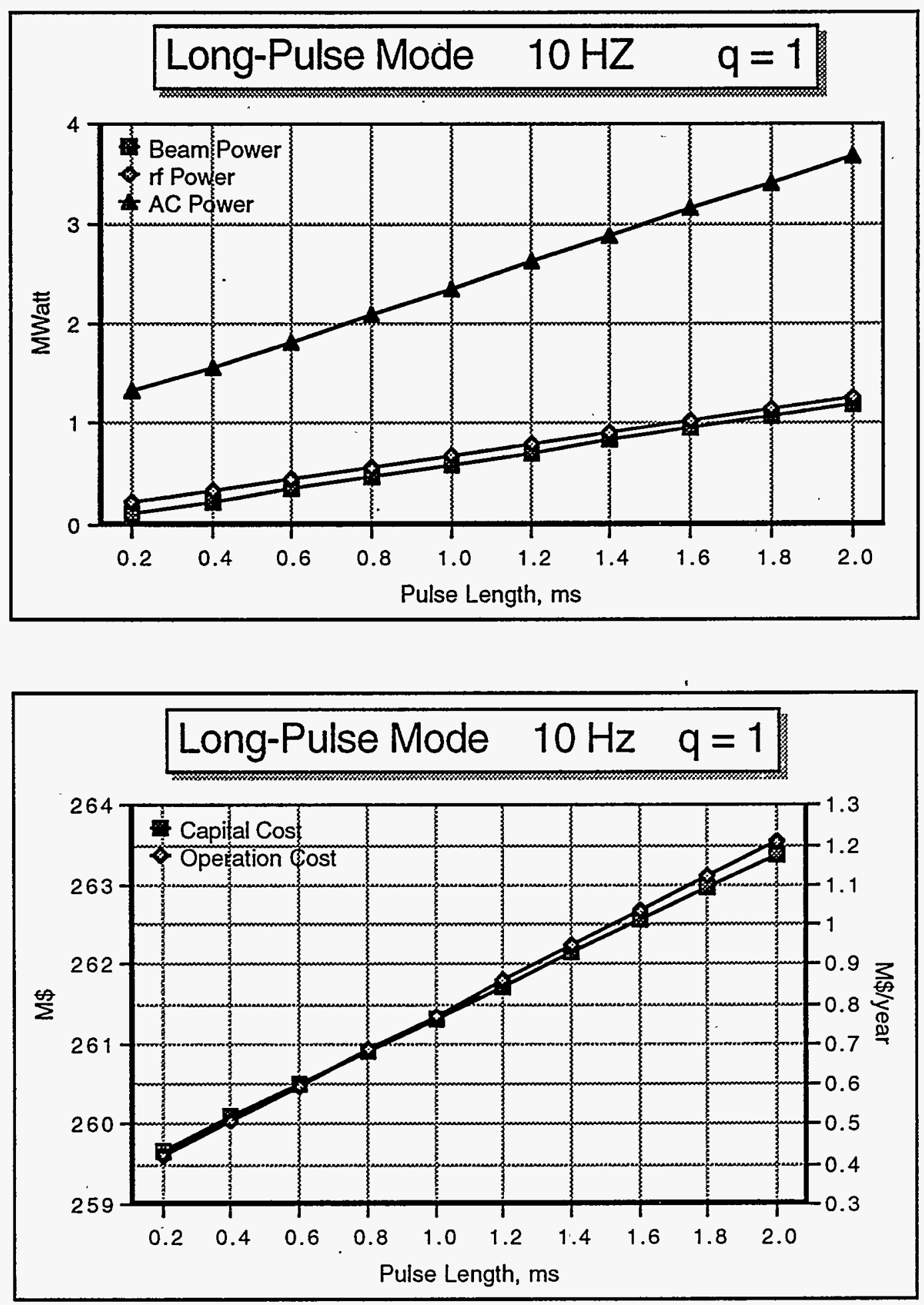

Figure 17. Power and Cost values for the Long-Pulse mode, unchopped, at $10 \mathrm{~Hz}$ repetition rate, versus beam Pulse Length $T_{p}$ 